\title{
Real-Time Tephra Detection and Dispersal Forecasting by a Ground-Based Weather Radar
}

\author{
Magfira Syarifuddin ${ }^{1, *}$, Susanna F. Jenkins ${ }^{1}$, Ratih Indri Hapsari ${ }^{2}$, Qingyuan Yang ${ }^{1}$, Benoit Taisne ${ }^{1}$, \\ Andika Bayu Aji ${ }^{1}$, Nurnaning Aisyah ${ }^{3}$, Hanggar Ganara Mawandha ${ }^{4}$ and Djoko Legono ${ }^{5}$
}

Citation: Syarifuddin, M.; Jenkins, S.F.; Hapsari, R.I.; Yang, Q.; Taisne, B.; Aji, A.B.; Aisyah, N.; Mawanda, H.G.; Legono, D. Real-Time Tephra Detection and Dispersal Forecasting by a Ground-Based Weather Radar. Remote Sens. 2021, 13, 5174. https://doi.org/ $10.3390 /$ rs13245174

Academic Editors: Ciro Del Negro, Michael S. Ramsey and Claudia Corradino

Received: 22 November 2021 Accepted: 15 December 2021 Published: 20 December 2021

Publisher's Note: MDPI stays neutral with regard to jurisdictional claims in published maps and institutional affiliations.

Copyright: (c) 2021 by the authors. Licensee MDPI, Basel, Switzerland. This article is an open access article distributed under the terms and conditions of the Creative Commons Attribution (CC BY) license (https:// creativecommons.org/licenses/by/ $4.0 /)$.
1 Earth Observatory of Singapore, Asian School of the Environment, Nanyang Technological University, Singapore 639798, Singapore; susanna.jenkins@ntu.edu.sg (S.F.J.); qingyuan.yang@ntu.edu.sg (Q.Y.); BTaisne@ntu.edu.sg (B.T.); ANDIKABA001@e.ntu.edu.sg (A.B.A.)

2 Department of Civil Engineering, State Polytechnic of Malang, Kota Malang 65141, Indonesia; ratih@polinema.ac.id

3 Centre for Volcanology and Geological Hazards Mitigation, Yogyakarta 55166, Indonesia; nurnaning.aisyah@esdm.go.id

4 Department of Agricultural and Biosystem Engineering, Faculty of Agricultural Technology, Gadjah Mada University, Yogyakarta 55281, Indonesia; hanggar.g.m@ugm.ac.id

5 Department of Civil and Environmental Engineering, Engineering Faculty, Gadjah Mada University, Yogyakarta 55284, Indonesia; djokolegono@ugm.ac.id

* Correspondence: magfira.syarifuddin@ntu.edu.sg

\begin{abstract}
Tephra plumes can cause a significant hazard for surrounding towns, infrastructure, and air traffic. The current work presents the use of a small and compact X-band multi-parameter (X-MP) radar for the remote tephra detection and tracking of two eruptive events at Merapi Volcano, Indonesia, in May and June 2018. Tephra detection was performed by analysing the multiple parameters of radar: copolar correlation and reflectivity intensity factor. These parameters were used to cancel unwanted clutter and retrieve tephra properties, which are grain size and concentration. Real-time spatial and temporal forecasting of tephra dispersal was performed by applying an advection scheme (nowcasting) in the manner of an ensemble prediction system (EPS). Cross-validation was performed using field-survey data, radar observations, and Himawari-8 imageries. The nowcasting model computed both the displacement and growth and decaying rate of the plume based on the temporal changes in two-dimensional movement and tephra concentration, respectively. Our results are in agreement with ground-based data, where the radar-based estimated grain size distribution falls within the range of in situ grain size. The uncertainty of real-time forecasted tephra plume depends on the initial condition, which affects the growth and decaying rate estimation. The EPS improves the predictability rate by reducing the number of missed and false forecasted events. Our findings and the method presented here are suitable for early warning of tephra fall hazard at the local scale.
\end{abstract}

Keywords: tephra; ground-based weather radar; Bayesian approach; nowcasting; ensemble prediction system

\section{Introduction}

Tephra is the fragmented material produced during an explosive volcanic eruption. Once in the atmosphere, the mix of tephra, volcanic gases, and ambient air forms a volcanic plume. Tephra is classified according to its size as volcanic bombs or blocks $(D \geq 64 \mathrm{~mm}$ or $\phi \leq-6)$, lapilli (2 $\mathrm{mm} \leq D<64 \mathrm{~mm}$ or $-1 \geq \phi>-6)$, coarse ash $(64 \mu \mathrm{m} \leq D<2 \mathrm{~mm}$ or $4 \geq \phi>-1)$, and fine ash $(D<64 \mu \mathrm{m}$ or $\phi>4)$, where $D$ is the diameter of the particle and $\phi \equiv-\log _{2} D(\mathrm{~mm})$. Tephra falls can damage buildings and cause disruption to human livelihoods, agricultural production, and other economic activities [1-3]. Because of the significance of the hazards posed by a tephra fall, its timely detection and tracking in the atmosphere is very important. 
Tephra can be detected and tracked in the atmosphere with ground-based weather radars operating at various wavelengths [4-7]. Tephra properties (concentration, fall rate, and diameter) have been retrieved by radar using a microphysical model of atmospheric scattering theorem, which assumed that tephra particles have similar characteristics to raindrops [8-11]. One of the radar applications that has not been explored thoroughly is its use as an extension to an early-warning system of spatial and temporal tephra dispersal. Up to now, only one study has documented the use of a weather radar for early-onset detection and tracking of tephra [6]. In this previous study, the detection of plume onset was achieved by coupling radar and an infrasound instrument. However, tracking of the plume excluded the sources and sink of radar observable [6]. As a result, the tephra plume's spatial movement (displacement) was monitored, but the observable radar values were constant through time, indicating a persistent presence of volcanic clouds in the atmosphere. A solution for this problem is applying a dynamic advection scheme, widely used for atmospheric precipitation forecasting [6], known as nowcasting [12-15]. Nowcasting is a spatial prediction method covering minutes to a few hours of rainfall forecasting based on radar advection vectors. This approach can forecast the rotation and deformation of the observed field and has been an essential prerequisite for real-time flash flood forecasting in operational hydrology [13].

Recently, the ensemble prediction system (EPS) has attracted the interest of modellers, as it can increase the robustness of forecasting results [14-16]. When applying the EPS, the nowcasting model is run multiple times from very slightly different initial conditions. Zidikheri et al. have applied this approach to the volcanic ash retrieval model to increase the predictability score of volcanic cloud dispersal forecasting for the 2014 Kelud and 2015 Rinjani eruptions [17]. Their study found that poorer prediction skills could result from using shorter time steps and an incorrect threshold of volcanic ash mass load. The later mentioned reason is related to the limitation of satellite monitoring, particularly at lower altitudes and in surrounding and overlying cloud features not involving ash, which could also account for the discrepancies in the low mass load regions [17]. Moreover, the satellite based-volcanic ash retrieval model requires some input parameters, e.g., the atmospheric profiles (pressure, temperature, and humidity), the surface temperature and emissivity, the volcanic cloud geometry (altitude and thickness), and the ash optical properties [18], which can complicate the calculation process. Contrarily, a weather radar scans the atmospheric information near surface level ( $<3000 \mathrm{~m}$ height) and relies on particle scattering theorem. Using solely radar data, some studies have managed to derive the real-time GSD and tephra concentration $[8-11,19]$. The radar estimates are valuable parameters in tephra dispersal modelling by the radar nowcasting approach.

This study presents the potency and uncertainty of real-time tephra plume detection and tracking applied to two eruption events of Merapi in 2018. First, we overcome previous limitations of unwanted clutter contaminating radar scanning data [20] by applying an automatic noise cancellation. Then, we coupled the modified tephra-radar retrieved model $[8,9,19,20]$ with the EPS of radar nowcasting. The evaluation was done by comparing the radar-based tephra properties (i.e., concentration and grain size) with ground-based data and satellite imagery. Through this study, the integration of EPS forecast products can contribute to the potential use of weather radar monitoring in the tephra fall early warning system, which is beneficial for local people living nearby Merapi.

\section{Methods}

\subsection{Radar Setting and Study Case}

A small-compact X-band dual-polarization Doppler weather multi-parameter (X-MP) of WR2100 type radar, manufactured by Furuno Electric Co., Nishinomiya City, Hyogo Prefecture of Japan, and was installed and operated at Merapi Museum $(7.5 \mathrm{~km}$ SW from Merapi's vent) in 2014-2019 (Figure 1). The main objective of the installation was for research in volcano hazards such as rain-triggered lahar $[16,21]$ and real-time tephra fallout rate [20]. Figure 1 presents the area covered by the $360^{\circ}$ radar scan of plan position indicator 
(PPI) strategy. In PPI scanning mode, the radar scans the volume of the atmosphere by changing the elevation angle in sequence every time it finishes one rotational scan. There were nine different elevation angles: $3,5,7,9,11,13,15,18$, and $21^{\circ}$. An entire volumetric scan sampled the atmosphere into 700 sweeps (beam motion), and each sweep had 300 range gates with a $150 \mathrm{~m}$ bin width. It requires 2 -min time intervals for a full volumetric PPI scan (all elevation angles). Radar data were heavily affected by ground clutter up to $13^{\circ}$ elevation angle scan (Figure 1 ). While the default clutter cancellation routine by radar can recognize the beam blockage [20], ground clutter may still occur as the result of direct contact between surface and sidelobes owing to the presence of Merapi and Turgo Hill in the SW sector (Figure 1, [20]). Sidelobes are unwanted returns from a direction outside the main lobe, which can bias the reflectivity intensity factor, Doppler velocity, and spectrum width estimates.
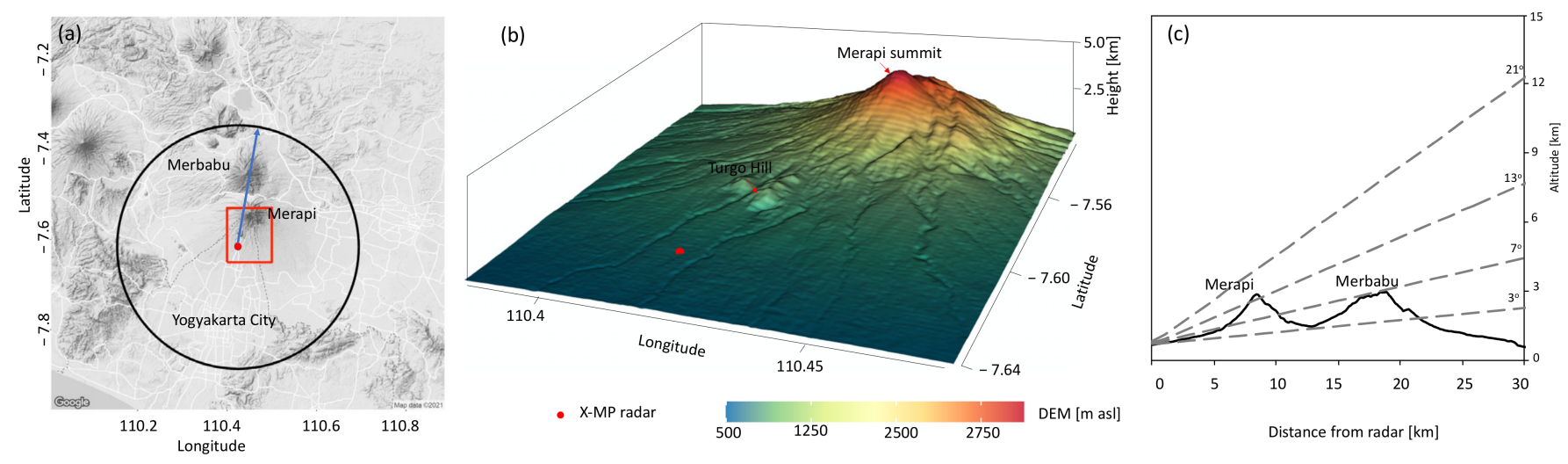

Figure 1. Left panel (a) is a fixed observation area of the PPI scan mode. Centre panel (b) is the 3D view of surface topography of the red square area in (a). Right panel (c) is the vertical profile of radar scan and topography, extracted along the blue arrow in (a). Identified in (a) are locations of Yogyakarta city, Merapi, and Merbabu. The locations of Turgo hill and Merapi summit are pointed by red arrows in (b) and the X-MP radar site is indicated by a red dot in $(\mathbf{a}, \mathbf{b})$.

Table 1 presents the specification of this small, compact, and light-weighted system. This ground-based weather radar is a dual-polarized system that transmits two different wavelength propagations: horizontal and vertical, giving multiple output parameters, listed in Table 1. Only two parameters were used in this study: the reflectivity intensity factor $Z_{H}$ and copolar correlation $\rho$. Reflectivity intensity in horizontal copolar propagation $Z_{H}$ measures the efficiency of a target to reflect (absorb and re-radiate) radar energy. The copolar correlation $\rho$ is the zero-lag correlation coefficient between horizontally $(H)$ and vertically $(V)$ transmitted and received copolar signals. This parameter shows the uniformity of the features being observed by the radar. Detailed explanations for each of the dual-polarized system's radar parameters have been discussed in [22]. The $Z_{H}$ parameter is widely used for tephra classification $[8,9,19,20]$, and $\rho$ produces the least false alarm in unwanted clutter identification [23]. Both $Z_{H}$ and $\rho$ were used to remove unwanted clutter, and only the filtered $Z_{H}$ was used for tephra detection and tracking, as explained in Sections 2.2 and 2.3 and Appendix A.

The selected study cases are two explosive events with the availability of X-MP radar data and in situ tephra grain size information [24], occurring on 11 May 2018 (M05) and 1 June 2018 (M06). Following Merapi's last centennial explosive eruption in 2010, the volcano experienced six phreatic eruptions between 2012 and 2014. The M05 event was the first minor explosion after four years of quiescence, starting in 2014. It occurred at 00:40 and lasted for $5 \mathrm{~min}$. Time is expressed in hhmm Coordinated Universal Time (UTC). The Centre for Research and Technology of Geological Disasters (Balai Penyelidikan dan Pengembangan Teknologi Kebencanaan Geologi-BPPTKG) officially reported it as a phreatic eruption. Prior to the eruption, there were no unequivocal precursory signals, which is common for this type of eruption. The event produced a $5.5 \mathrm{~km}$ high (above its summit) eruption column with explosion energy of $17 \mathrm{MJ}$ [25]. 
Merapi continued its eruptive activity between 21 and 24 May 2018, by producing multiple explosions. This series of short-lived eruptions ended on 1 June 2018, marked by three explosions that occurred on the same day. The M06 event was the first eruption on that day and had the greatest intensity of the three, occurring at 01:20 UTC for a 2 min duration [26]. The eruption produced a $6 \mathrm{~km}$ high eruption column with explosion energy of $46 \mathrm{MJ}$ [25]. Subsequently, Merapi's activities shifted to be more magmatic, marked by the appearance of a new lava dome in August 2018.

Table 1. Radar specification used in the study [27].

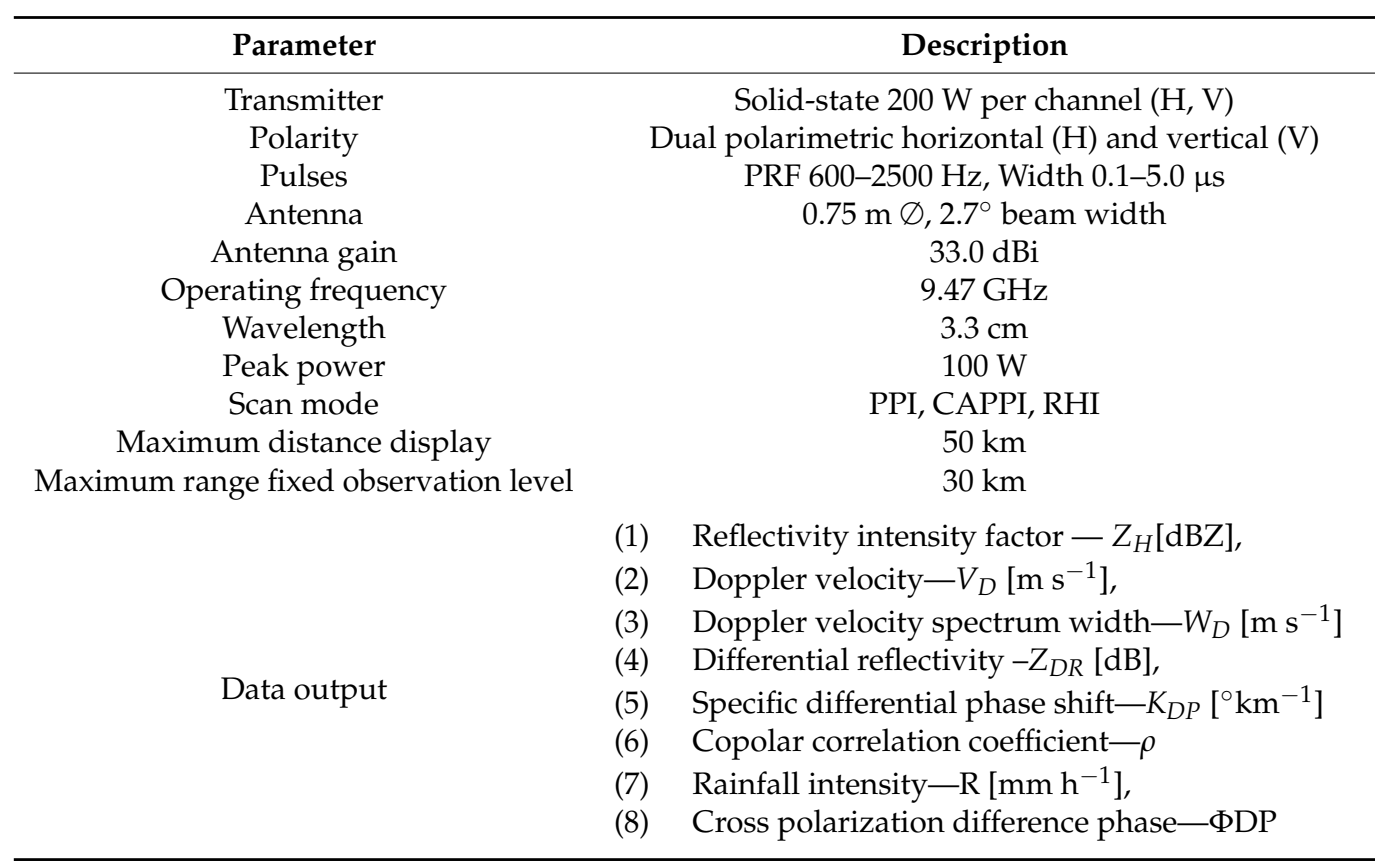

Another reason for selecting these explosive events was the different spatial distributions of the pyroclastic deposit. The deposit of tephra fall from M05 was found in the S sector, while M06 deposits were deposited in the NW sector from Merapi [24]. While being small in magnitude (volcanic eruptive index, VEI-1), satellite images captured both cases (Appendix C: Figure A2), meaning that the reliability of the EPS results could be evaluated.

We used a set of radar data of $56 \mathrm{~min}$, ranging from $4 \mathrm{~min}$ before to $52 \mathrm{~min}$ after the onset. Hence, it gave a range of time scans at 00:36-01:30 (M05) and 01:16-01:20 (M06). This time range selection was based on visual verification of tephra visibility on radar images. We also found that the plume was only detected at $13-21^{\circ}$ elevation angles.

\subsection{Tephra Detection}

The detection of the volcanic cloud was performed by identifying radar echoes of the tephra from non-tephra echoes. Although both cases occurred during clear days, nontephra noises still occurred because of sidelobe contamination, anomalous propagation, and the presence of ground clutter. Anomalous propagation results from false radar echoes during calm, stable atmospheric conditions, often associated with super refraction in a temperature inversion, which directs the radar beam toward the ground. We applied a clutter cancellation procedure based on naïve Bayesian classifier to solve the previously mentioned problems [28].

The naïve Bayesian classifier (NBC) is a supervised technique, which implements the classification based on the posterior probability that certain observed measurements correspond to a specific class. In the clutter cancellation process, the unwanted clutters were divided into three classes: the non-clutter data $(c=0)$, clutter $(c=1)$, and invalid data $(c=-99)$. The third class was introduced based on the radar signal/beam blocking identified by the Furuno default rain-map program [21]. For our study, only data corre- 
sponding to the non-clutter class were recognized as valid and used for tephra detection and tracking.

The 2D spatial data of $Z_{H}$ were used as the input parameter in the volcanic ash retrieval radar model (VARR, [8,9]). This method is a two-step stepwise approach radar microphysical model, using the scaled gamma distribution. The main assumptions of this method are that tephra particles have a spherical shape and that the scattering of electromagnetic waves follows the Rayleigh theorem [8,9]. Only coarse ash to lapilli regimes were identified by this type of radar $[19,20]$, resulting in two different tephra class regimes: fine $(\mathrm{F})$ and coarse $(\mathrm{C})$ particles. These two terms should be distinguished from finer ash and coarser ash regimes, mentioned in Section 1, as our classification identified class $\mathrm{F}$ as a class for particle diameter ranging from $0.015 \mathrm{~mm}$ to $0.35 \mathrm{~mm}$ and class $C$ for particle diameter ranging from $0.35 \mathrm{~mm}$ to $6 \mathrm{~mm}$. This range was generated based on the previous study $[8,9,19,20]$. Table A1 presents detailed information about tephra classification. The clutter cancellation and radar-tephra retrieved model are discussed intensively in [28] and $[8,9,19]$, respectively; hence, only a brief description is presented in Appendix B for convenience. The reproducible code is available in Supplementary Materials.

\subsection{Nowcasting and Ensemble Prediction System}

Tracking of tephra was performed by adopting the radar's observable extrapolation model, originally known as the translation model [12]. We assumed radar scan representing the surface level. In meteorology, the radar's constant altitude PPI (CAPPI) data are widely used to estimate the surface level of rainfall intensity. However, there is no agreement regarding which radar product should be used to estimate tephra properties. Essentially, CAPPI is the 3-dimensional (3D) interpolated data of PPI, and some studies have used this type of data to estimate the tephra fallout rate [20,29]. Meanwhile, other studies have used the lowest PPI elevation angle data to estimate the accumulated tephra deposit $[30,31]$. In this study, we used the maximum aggregates of radar observable as suggested in [32]. The maximum $Z_{H}$ is usually related to the densest concentration of tephra [31]. For each 2 min time acquisition of the PPI scan, we calculated the maximum aggregate of tephra concentration across elevation angles of $13-21^{\circ}$. This aggregate value was compiled as gridded 2D (150 m mesh) spatial data. The use of a maximum aggregate was also used to tackle the problem of wavelength sensitivity, which caused the underestimation of retrieved tephra properties $[20,33]$. Using the tephra concentration, estimated from $Z_{H}$, we could simplify the forecast of tephra dispersion. This approach did not require the atmospheric condition and ESP information. We used the estimated tephra concentration from the tephra detection framework to estimate the dynamic of its distribution along the $x$ and $y$ directions and time $t$ as follows:

$$
\frac{\partial C_{a}}{\partial t}+m \frac{\partial C_{a}}{\partial x}+m \frac{\partial C_{a}}{\partial y}=w
$$

where $m=d x / d t$ and $n=d y / d t$ are radar advection vectors and $w=d C_{a} / d t$ is the radar echo growth and decaying rate (source/sink term). The spatial coordinate $(x, y)$ represents easting and northing UTM, respectively. Variables $m, n$, and $w$ are defined in Equations (2)-(4).

$$
\begin{aligned}
& m(x, y)=c_{1} x+c_{2} y+c_{3} \\
& n(x, y)=c_{4} x+c_{5} y+c_{6} \\
& w(x, y)=c_{7} x+c_{8} y+c_{9}
\end{aligned}
$$

Ensemble forecasting or EPS could help to get a feeling for the possibilities of pattern evolution. In Equations (2)-(4), $c_{1}-c_{9}$ parameters were optimized by linear least square using past estimated tephra concentration, whereas in this case, the first 4-8 min detected plume captured in radar images. Nowcasting could be run according to different phenomena, which led to different ensemble member scenarios (Table 2). Considering the 
importance of the growth and decay rate to accommodate the sources and sinks of plume presence in the atmosphere, we selected phenomena 4 and 5 in Table 2. For each advection phenomenon, the ensemble member was modelled by various sets of time-lagged forecasts starting at different initial times [34]. As the first visible plume on radar imageries occurred simultaneously at the eruption onset and considering the importance of past observed radar data in generating the advection scheme, the selected initial condition was then decided at 4, 6, and 8 min after the reported onset. Thus, each case had six members, and its subsequent times were separated by 2 min intervals. The nowcasting model was run up to $44 \mathrm{~min}$ after the eruption onset, as it followed the presence of detected plume in observed radar data. The mean ensemble was obtained by calculating the mean of all members, using the time average of spatial data at each point $(x, y)$. All results were projected and visualized in WGS 84 coordinate system by rgdal and ggmap libraries of RStudio [35,36].

Table 2. Combinations of advection vectors parameter, adopted from different rainfall phenomena [15].

\begin{tabular}{|c|c|c|c|c|c|c|c|c|c|c|}
\hline No & Phenomena & $c_{1}$ & $c_{2}$ & $c_{3}$ & $c_{4}$ & $c_{5}$ & $c_{6}$ & $c_{7}$ & $c_{8}$ & $c_{9}$ \\
\hline 1 & Parallel translation & & & $x$ & & & $X$ & & & \\
\hline 2 & Parallel translation and rotation & $X$ & $x$ & $x$ & $X$ & $x$ & $X$ & & & \\
\hline 3 & Rotation & $x$ & $x$ & & $x$ & $x$ & & & & \\
\hline 4 & Parallel translation, growth-decay & & & $X$ & & & $X$ & $X$ & $X$ & $x$ \\
\hline 5 & $\begin{array}{c}\text { Parallel translation, rotation, } \\
\text { growth-decay }\end{array}$ & $X$ & $x$ & $X$ & $X$ & $x$ & $X$ & $X$ & $x$ & $x$ \\
\hline
\end{tabular}

\subsection{Evaluation}

The reliability of a predictive approach that considers uncertainty was examined, visually and quantitatively, through the verification of those members and observation from radar and Himawari-8. The observed concentration was derived from the valid $Z_{H}$ data, i.e., the filtered data after removing unwanted clutter. Himawari-8 is a satellite operated by Japan Meteorological Agency (JMA) since 2014, which observes the earth from $80^{\circ} \mathrm{E}$ to $160^{\circ} \mathrm{W}$ and between $60^{\circ} \mathrm{N}$ and $60^{\circ} \mathrm{S}$. The Advanced Himawari Imager (AHI) is an optical radiometer onboard the Himawari-8. Its full-disk observation covers 16 spectral bands from visible to infrared (IR) wavelengths. The spatial and temporal resolutions are $2 \mathrm{~km}$ and $10 \mathrm{~min}$, respectively [37]. We assumed this setting caused the Himawari-8 data to be at least $10 \mathrm{~min}$ behind radar data or real-time. The standard Himawari-8 data were retrieved from the P-Tree system, managed by the Japan Aerospace Exploration Agency (JAXA) Earth Observation Research Centre (EORC) and JMA. This study used the temperature band difference of band $13\left(\mathrm{BTD}_{\mathrm{B} 13}\right)$ as the red beam of $\mathrm{BTD}_{\mathrm{B} 13-\mathrm{B} 15}$ was found to be effective for detecting dust and volcanic ash [38]. The identified tephra plume was defined by lower than $285 \mathrm{~K}$ cloud temperature above the coordinates of Merapi, which is the temperature at $3-5 \mathrm{~km}$ asl height. The $2 \mathrm{D}$ gridded data of Himawari- 8 were then transformed into a polygon to delineate the fraction of cloud identified as tephra plume.

Two widely used dichotomous indices were applied: the critical success index (CSI) and the probability of detection $(P O D)$. They were given by the following formulas (Equations (5) and (6)), along with a confusion matrix presented in Table 3. Here, $N_{h i t}$ is the number of hit events from the contingency table, $N_{\text {miss }}$ is the number of miss events, and $N_{\text {false }}$ is the number of false events as defined in Table 2. The values of these indices have the range $0-1$, where " 1 " represents a perfect forecast.

$$
\begin{gathered}
C S I=\frac{N_{\text {hit }}}{N_{\text {hit }}+N_{\text {miss }}+N_{\text {false }}} \\
P O D=\frac{N_{\text {hit }}}{N_{\text {hit }}+N_{\text {miss }}}
\end{gathered}
$$


Table 3. The $2 \times 2$ confusion matrix [39].

\begin{tabular}{lccc}
\hline \multirow{2}{*}{$2 \times 2$ Confusion Matrix } & \multicolumn{2}{c}{ Event Observed } \\
\cline { 3 - 4 } & YES & YES & NO \\
\hline \multirow{2}{*}{ Event Forecast } & NO & Hit & Miss \\
& False & Hit \\
\hline
\end{tabular}

Regarding probabilistic prediction, to date, the most common metric for assessing accuracy is the Brier score [40]:

$$
B S=\frac{1}{n} \sum_{k=1}^{n}\left(y_{k}-o_{k}\right)^{2}
$$

where $y$ is the fraction of members that forecast the event, $o$ is the actual outcome of the event (" 1 " if it occurs and " 0 " if it does not occur), and $n$ is the number of forecasting pairs that are spatial. The score of a perfect forecast was " 0 ". This index was applied to assess probabilistic tephra concentration nowcasting that was equal to or greater than $0.01 \mathrm{~g} / \mathrm{m}^{3}$. This threshold equalled the lower limit of generated synthetic data (Table A2).

\section{Results}

\subsection{Volcanic Ash Detection}

Figure 2 shows the results of the Bayesian classifier for tephra detection on M05 and M06 at 2 min after the onset. All used $Z_{H}$ were cleaned from unwanted clutter by NBC, given by some examples presented in Figure A1. All particle size classes (ash and lapilli) were identified at the onset of the eruption. The highest $Z_{H}$ regimes ( $\left.>50 \mathrm{dbZ}\right)$ were associated with the coarse class with the most intense concentration of $C_{a}>7.5 \mathrm{~g} / \mathrm{m}^{3}$. Relatively equal $C_{a}$ was also obtained by finer class of intense concentration, although it was given by $\sim 35 \mathrm{dBZ} Z_{H}$.
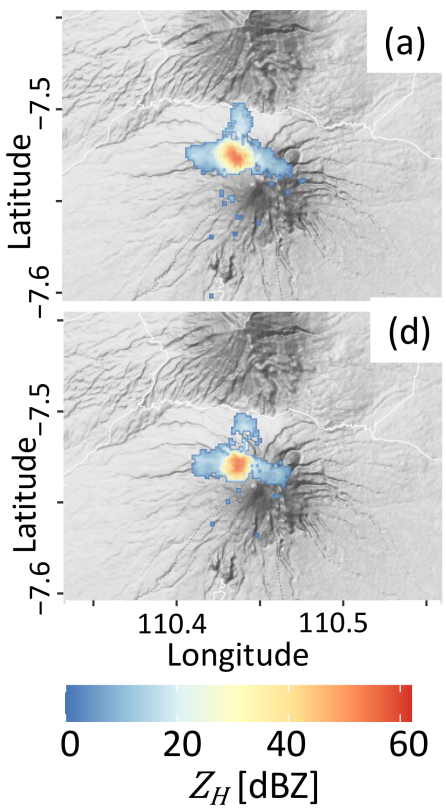
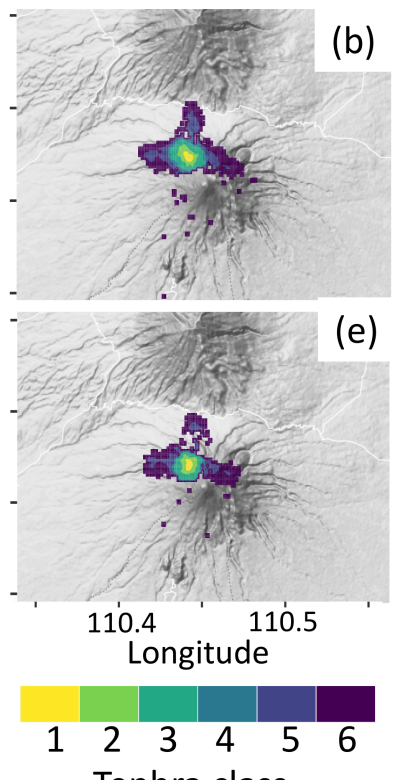

(e)

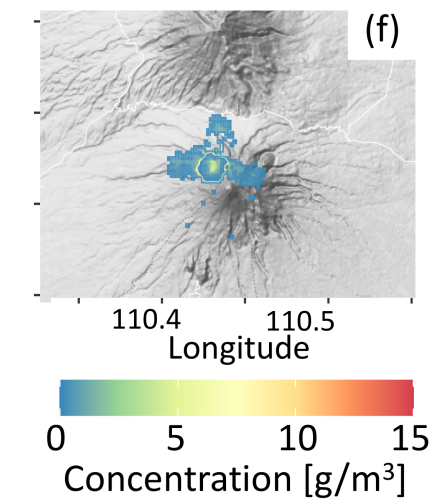

Figure 2. Tephra detection using modified VARR model (Appendix A and Appendix B) for M05 (first row) and M06 (bottom row) at 2 min after the reported eruption onset. From the left, the first column $(\mathbf{a}, \mathbf{d})$ is the reflectivity intensity factor, the second column $(\mathbf{b}, \mathbf{e})$ is the tephra classes, and the third column $(\mathbf{c}, \mathbf{f})$ is the tephra concentration. Tephra classes $(\mathbf{b}, \mathbf{e})$ of $1-3$ represent the coarse class $(C)$ of light, moderate, and intense concentration, respectively. Tephra classes of 4-6 represent the same tephra concentration, but for the finer class $(\mathrm{F})$. 
The spatial and temporal evolutions of radar-retrieved tephra grain size at selected time stamps are given in Figures 3 and 4 . For both cases, plumes were identified from $0 \mathrm{~min}$ after reported onset up to more than $40 \mathrm{~min}$ and $20 \mathrm{~min}$ after onset, respectively. The radar-retrieved tephra had particle diameters ranging from 0.02 to $2.3 \mathrm{~mm}$ or $\phi=1.7$ to -0.83 (Figures 3 and 4), indicating the limitation of the used X-MP radar in detecting finer particle regimes. Particles larger than $2 \mathrm{~mm}$ (lapilli regime) were retrieved from $Z_{H}$ until up to 4 min after the onset (Figures 3 and 4 ).
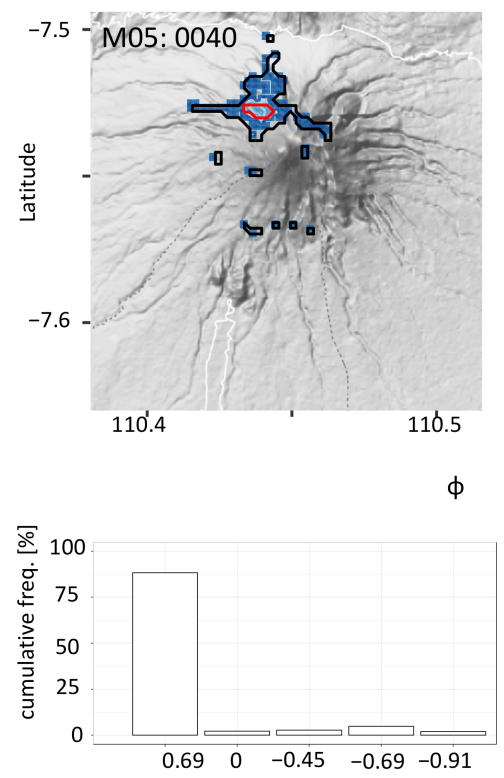
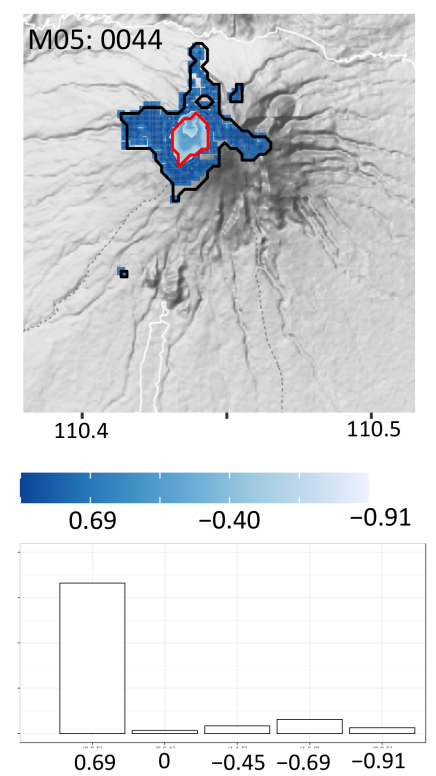

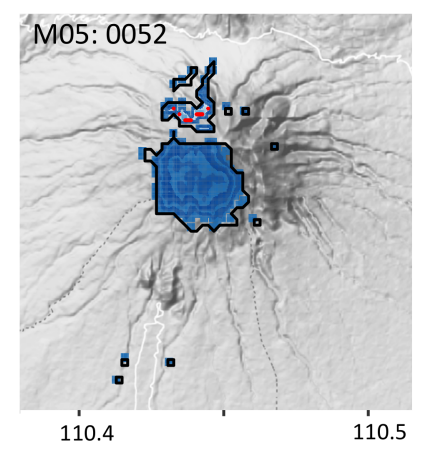

$\phi-2.3$

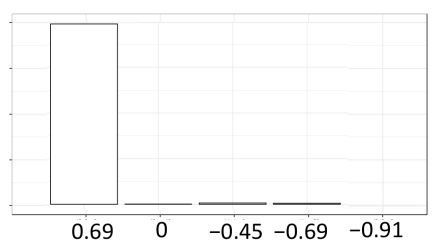

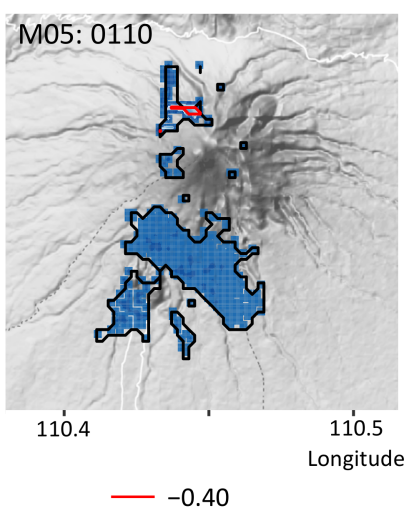

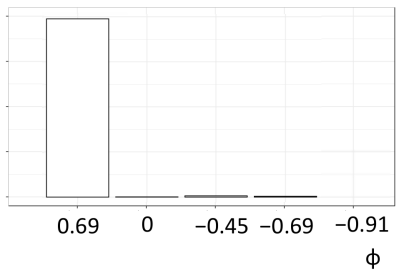

Figure 3. The first row is the spatial distribution of the estimated radar-retrieved mean diameter of M05 at different time stamps. The second row is the corresponding cumulative grain size (in $\phi$ ) for each time stamp. In each image on the second row, the $x$-axis is the lower limit of $\phi=-\log _{2} D$.

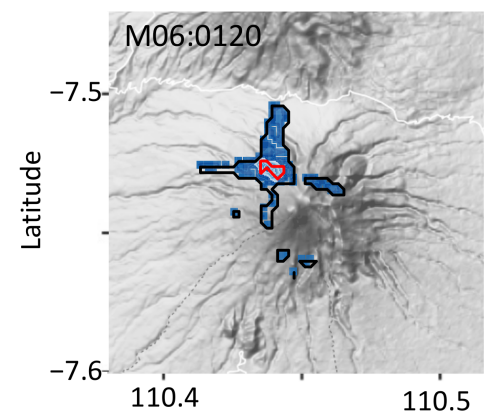

$\phi$

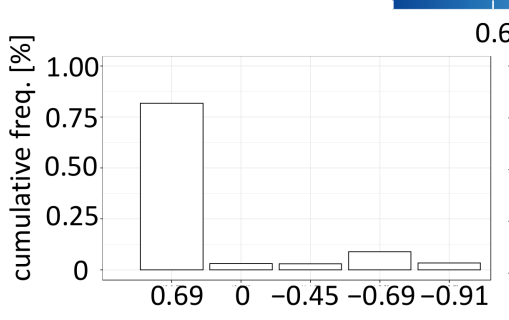

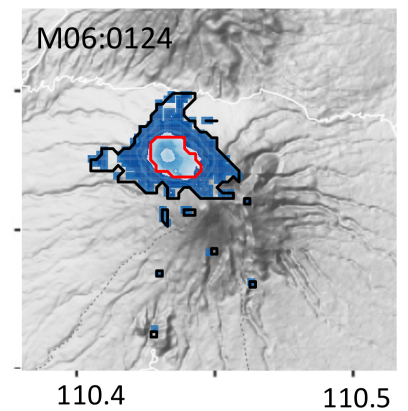

$-0.91$

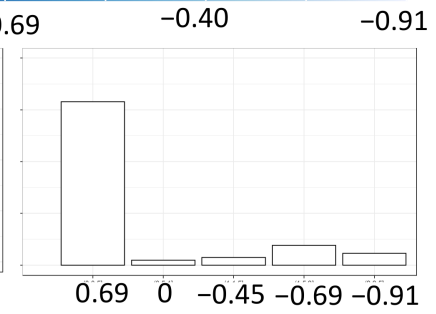

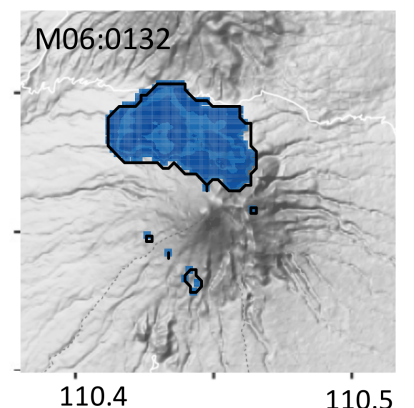

$\phi$
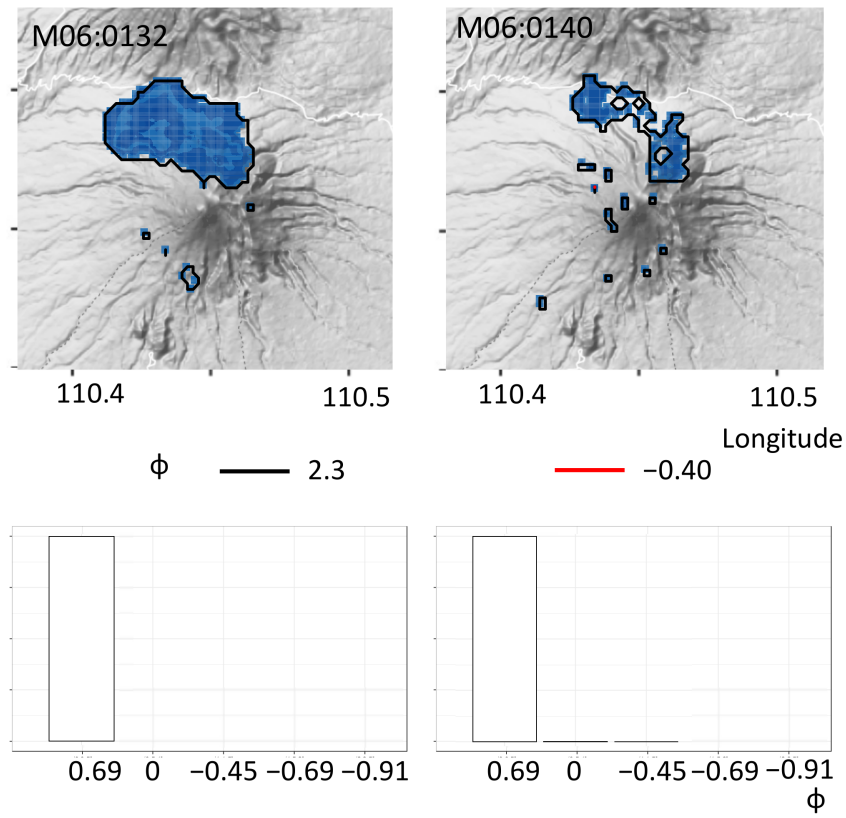

Figure 4. The first row is the spatial distribution of the estimated radar-retrieved mean diameter of M06 at several time stamps. The second row is the corresponding cumulative grain size for each time stamp. In each image on the second row, the $x$-axis is the lower limit of $\phi=-\log _{2} D$. 
Grain size distributions (in $\phi$ ) of the tephra deposits at sample sites near the volcano [24] and the extracted from the radar retrieved model are presented in Figure 5. We extracted the radar-retrieved GSD at Q-01 and Q-09 and found the spatial distribution of estimated GSDs were relatively in agreement with in situ sample-based data. We extracted more coarser particles' regimes ( $\phi=0.85-1.0)$ of the radar-based model at Q-01 (closer to the source) than at Q-09 (distant to the source). About $80 \%$ of radar-retrieved GSD at Q-09 was finer particle regimes, ] $\phi$ ranging from 1.00 to 1.25 (Figure 5c). For M05, the in situ data points in [24] were available at P-01 and P-09. Unfortunately, the retrieved GSD from $Z_{H}$ did not produce any data from these two points. The $Z_{H}$ parameter at those points was probably eliminated following the unwanted clutter removal (Figure 2c, $\mathrm{d}$ and Figure A1). However, we could retrieve GSD from P-02 to P-05 and merge their values to represent the GSD for M05. P-02 to P-04 are close to P-01, indicating the extracted GSD at P-02 to P-04 may fall within the GSD range to P-01. P-05 is a few km away from P-01 and the source, so it might produce a finer GSD regime than P-01. Combining all available extracted values at P-02 to P-05 may help characterize the GSD of M05. In Figure 5d, the merged radar-retrieved GSD of M05 is coarser than M06, where $100 \%$ of them fall within the range of $0.85-1.0 \phi$.
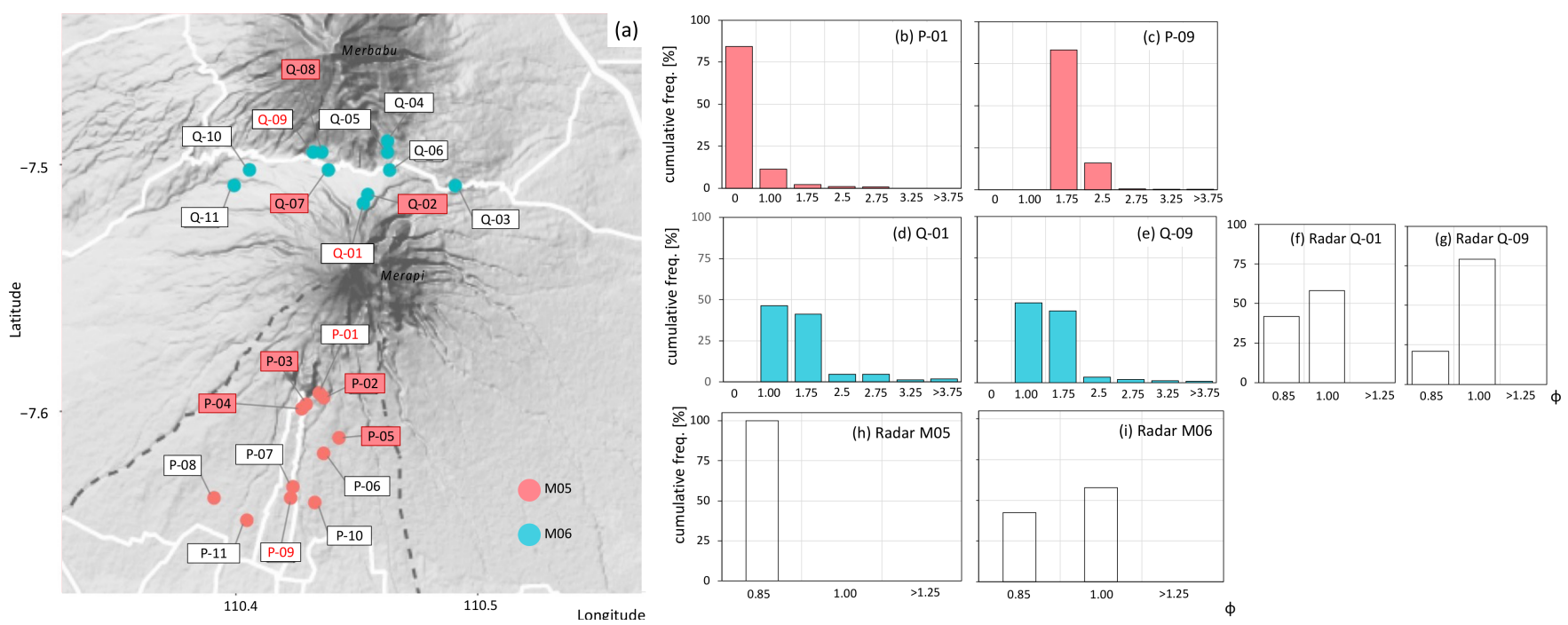

Figure 5. Left image (a) is the location of in situ sampling points of grain size $(\phi)$ for both event cases, digitized from [24]. Available data in [24] are Q-01, Q-09, P-01, and P-09, as presented in the cumulative frequency of GSD in (b-e) as indicated in the top right panel. M05 is given by P-01 and P-09 and M06 is given by Q-01 and Q-09 (M06). The cumulative frequency GSDs in (f,g) are extracted from radar-retrieved GSD for Q-01 and Q-09 (M06), respectively. Panels (h,i) give the cumulative frequency of GSD M05 (data are merged from P-01, P-02, P-03, P-04, and P-05) and M06 (data are merged from Q-01, Q-02, $\mathrm{Q}-07, \mathrm{Q}-08$, and Q-09). The $x$-axis on the GSD histogram is the lower limit of $\phi=-\log _{2} D$.

\subsection{Forecasting of Plume Dispersion}

Figures 6 and 7 present the 2D nowcasting tephra concentration results of plume dispersion. Figures A3 and A4 (Appendix C) present some of the ensemble members of nowcasting scenarios of M05 and M06, respectively. The presence of higher than $0.01 \mathrm{~g} / \mathrm{m}^{3}$ $C_{a}$ plume by mean EPS agrees with the retrieved $C_{a}$ observable from the radar, where their visuals disappear at almost the same time. More than 90\% of tephra in M05 disappear 30 min after the eruption onset. Mean EPS and estimated $C_{a}$ of M06 are unseen at 24 min after the onset. The forecasted $C_{a}$ of M05 becomes deviated at 01:06, presented by some part of the plume going $\mathrm{SE}$, while the other part is elongated to the $\mathrm{S}$ sector. Part of the plume moving to SE sector in M05 is given by the Onset+8_Sc5 (Figure A3). On the other hand, the forecasted EPS plume of M06 consistently dispersed in a circular shape and followed the displacement of radar retrieved $C_{a}$. Both EPS and radar-retrieved $C_{a}$ agreed that greater than $5 \mathrm{~g} / \mathrm{m}^{3} C_{a}$ existed for less than $10 \mathrm{~min}$ in the atmosphere. 


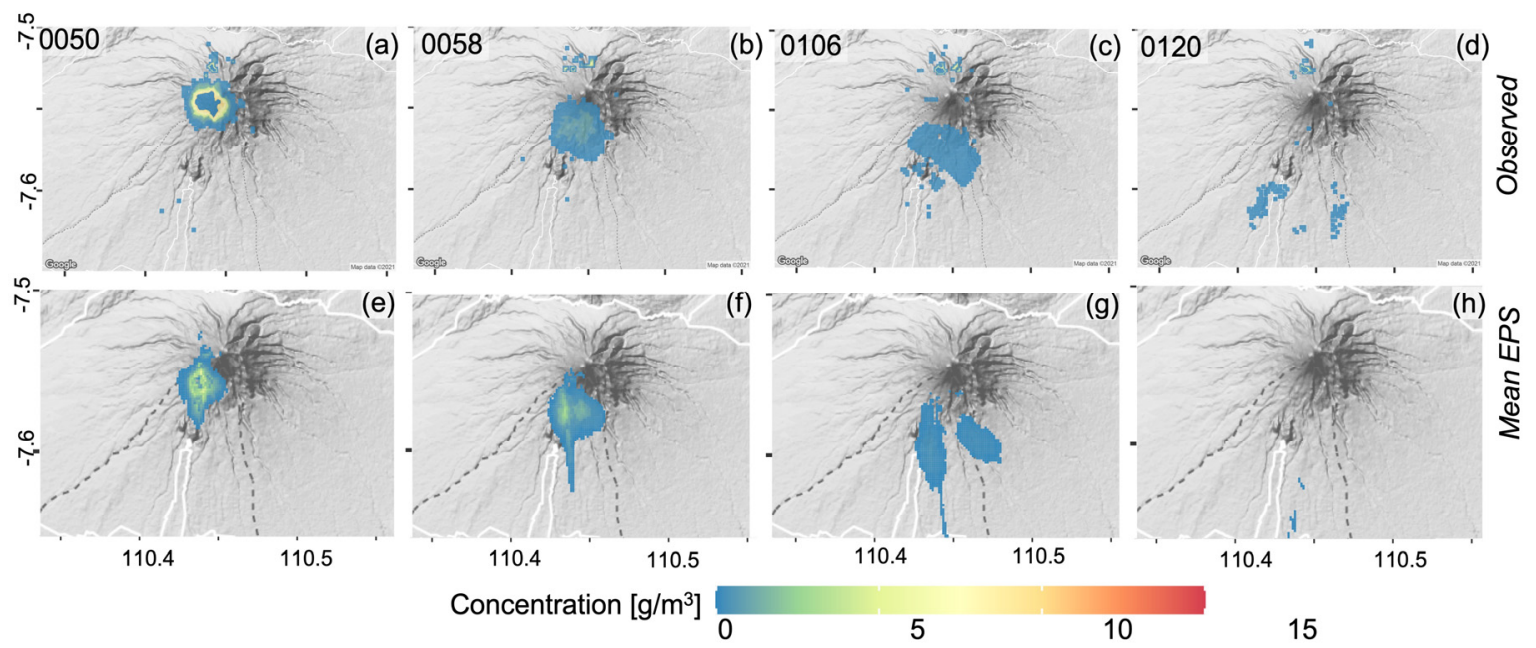

Figure 6. The retrieved tephra concentration on M05 based on valid $Z_{H}(\mathbf{a}-\mathbf{d})$ compared with the mean EPS (e-h) at different time steps, as indicated in the top left corner. The mean EPS uses a threshold of tephra concentration $\geq 0.01 \mathrm{~g} / \mathrm{m}^{3}$. In each image, the $x$-axis is longitude and $y$-axis is latitude.

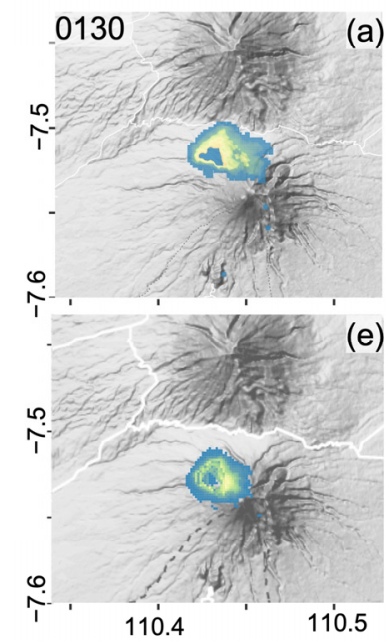

(a) 0134

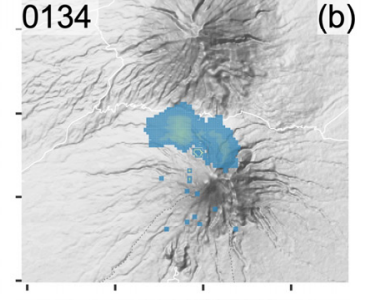

(e)

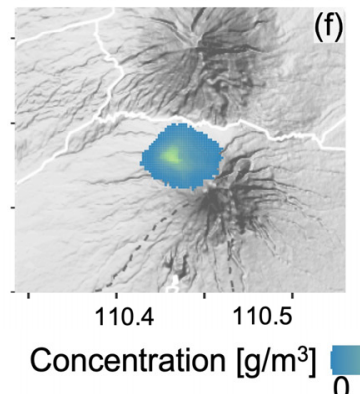

(b)

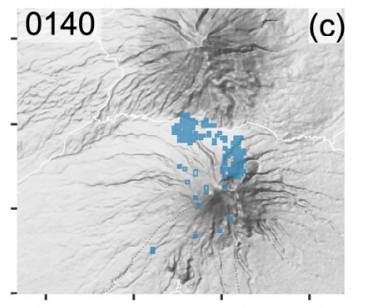

(g)

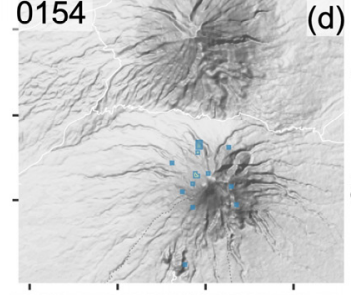

(h)
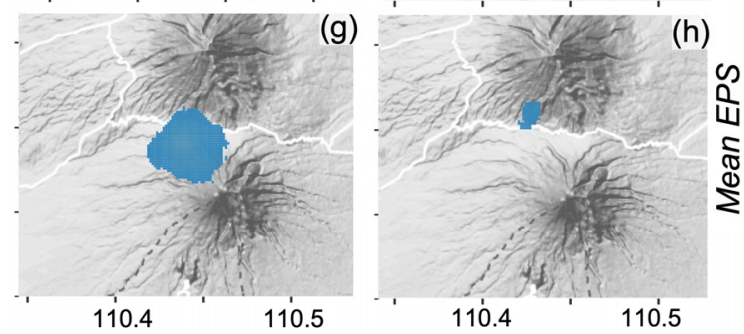

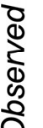

15

Figure 7. The retrieved tephra concentration on M06 based on valid $Z_{H}(\mathbf{a}-\mathbf{d})$ compared with the mean EPS (e-h) at different time steps, as indicated in the top left corner. The mean EPS uses a threshold of tephra concentration $\geq 0.01 \mathrm{~g} / \mathrm{m}^{3}$. In each image, the $x$-axis is longitude and $y$-axis is latitude.

\subsection{Evaluation}

The predictability scores are presented by CSI, POD, and BS. Both CSI and POD are given in Figure 8, while $B S$ is shown in Figure 9. In the case of $B S$, we also calculated the score by comparing the ensemble members with Himawari- 8 data. The area of volcanic ash identified by Himawari- 8 overlying the mean EPS results is presented in Figure 8 . Predictability indices generally agree that the highest uncertainty was given by the pair of onset +8 min and Sc 5 members. 

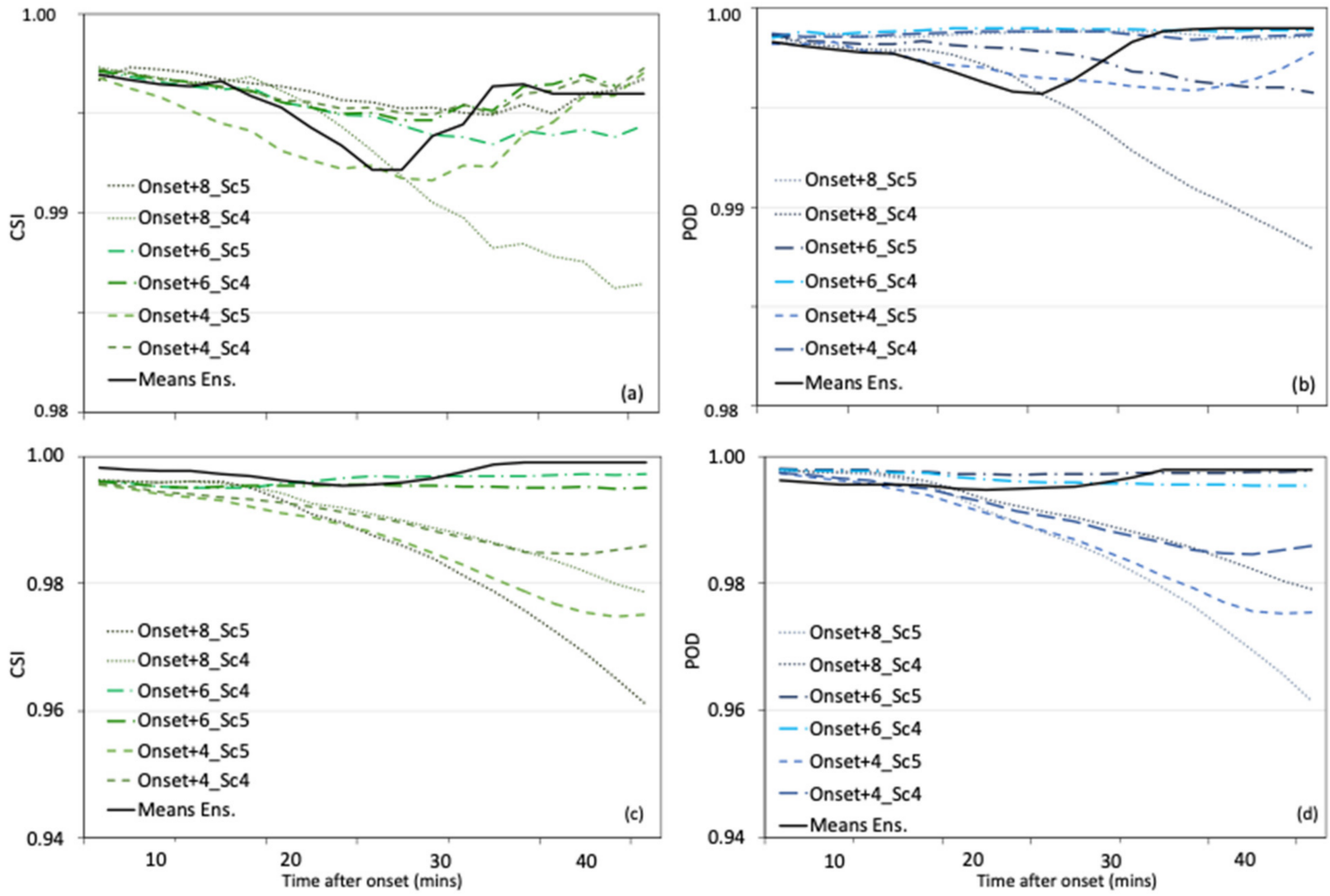

Figure 8. Spaghetti plots of CSI (left) and POD (right) for both study cases. (a,b) M05 and (c,d) M06. The ensemble member was named based on IC: onset+i_Scj, where $i$ and $j$ represent the time in minutes and advection phenomena (Table 2), respectively.

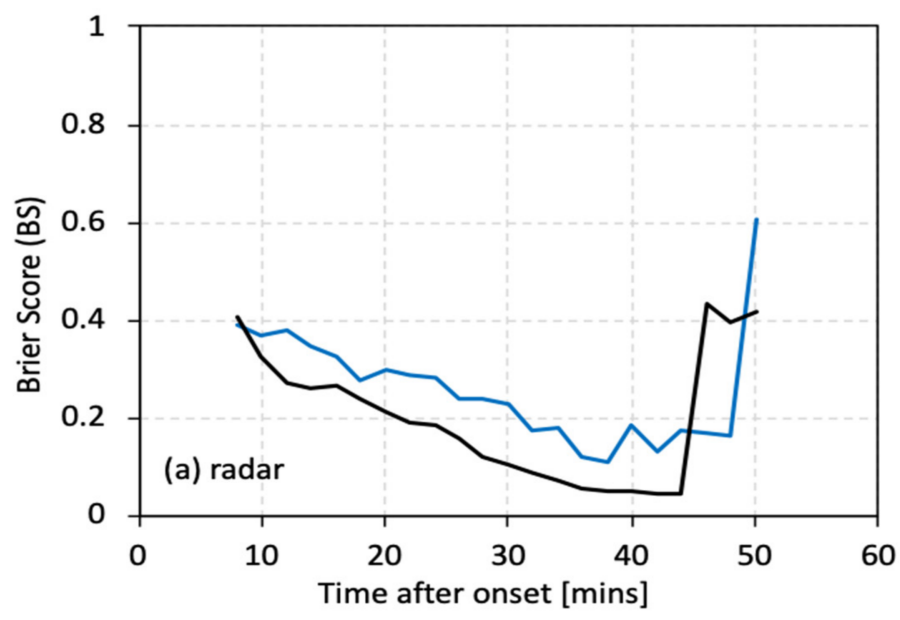

M05

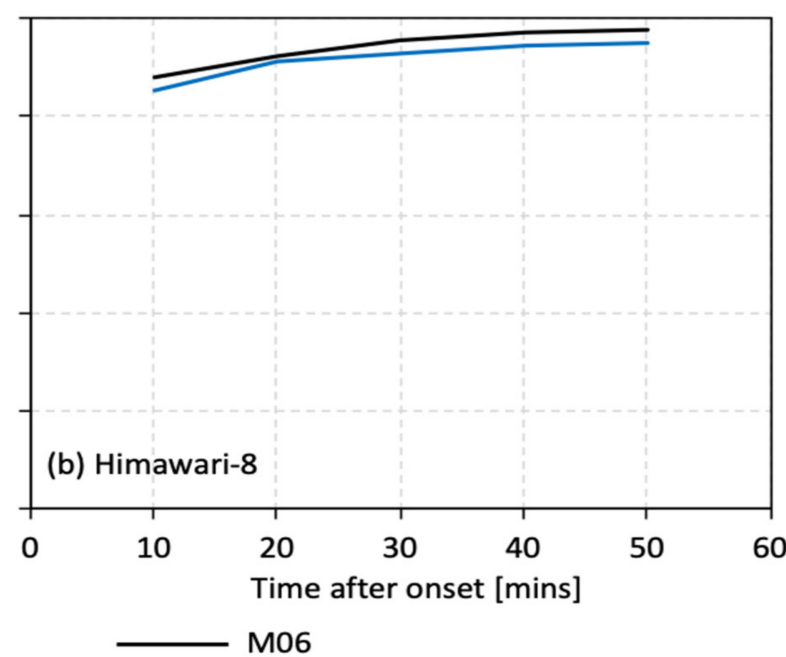

M06

Figure 9. Brier score of tephra plume tracking by mean EPS of M05 and M06 based on the pair analysis with (a) radar and (b) Himawari-8. Each EPS was generated using six members.

In general, the EPS of M05 has a better predictability rate than M06, according to CSI and POD. On the contrary, the BS of M06 mean EPS is better than M05. However, we consider that $B S$ provides more reliable results for the predictability rate as it only counts pairs of occurrence and non-occurrence events (Equation (5)). The CSI and POD scores decreased over time, but then increased, indicating the failure estimation of correct growth and decaying rate of some members. The cross-validation of the observed radar involving 
all ensemble members increases the predictability rate until $40 \mathrm{~min}$ after the onset, with BS ranging at 0.4 to 0.2 . After $40 \mathrm{~min}$, the model performance becomes significantly poorer because of the accumulated error of incorrect growth decaying rate given by some ensemble members. Although all the predictability rate parameters indicate the tendency of skill to decrease with time, we still highlight the importance of EPS in improving the accuracy of the tephra forecast, as it can maintain the CSI and POD to be greater than 0.99 for entire prediction time-steps.

Comparing the temporal and spatial of mean EPS to Himawari-8 data (Figure 10) gives the impression that the use of weather radar is limited in detecting the finest regime of the plume. The radar-based EPS did not give the same spatial tephra distribution as Himawari-8 data, especially in the $S$ sector. However, the EPS modelled the displacement of the plume that matched with the in situ sampling points better than Himawari-8 data (Figure 10). In Figure 9b, the cross-validation of the ensemble members with cloud temperature (Himawari-8) gives BS ranging from 0.85 to 0.90 within the first 20 min after the onset. Ten minutes later, the predictability skill becomes poorer, given by greater than $0.95 \mathrm{BS}$.
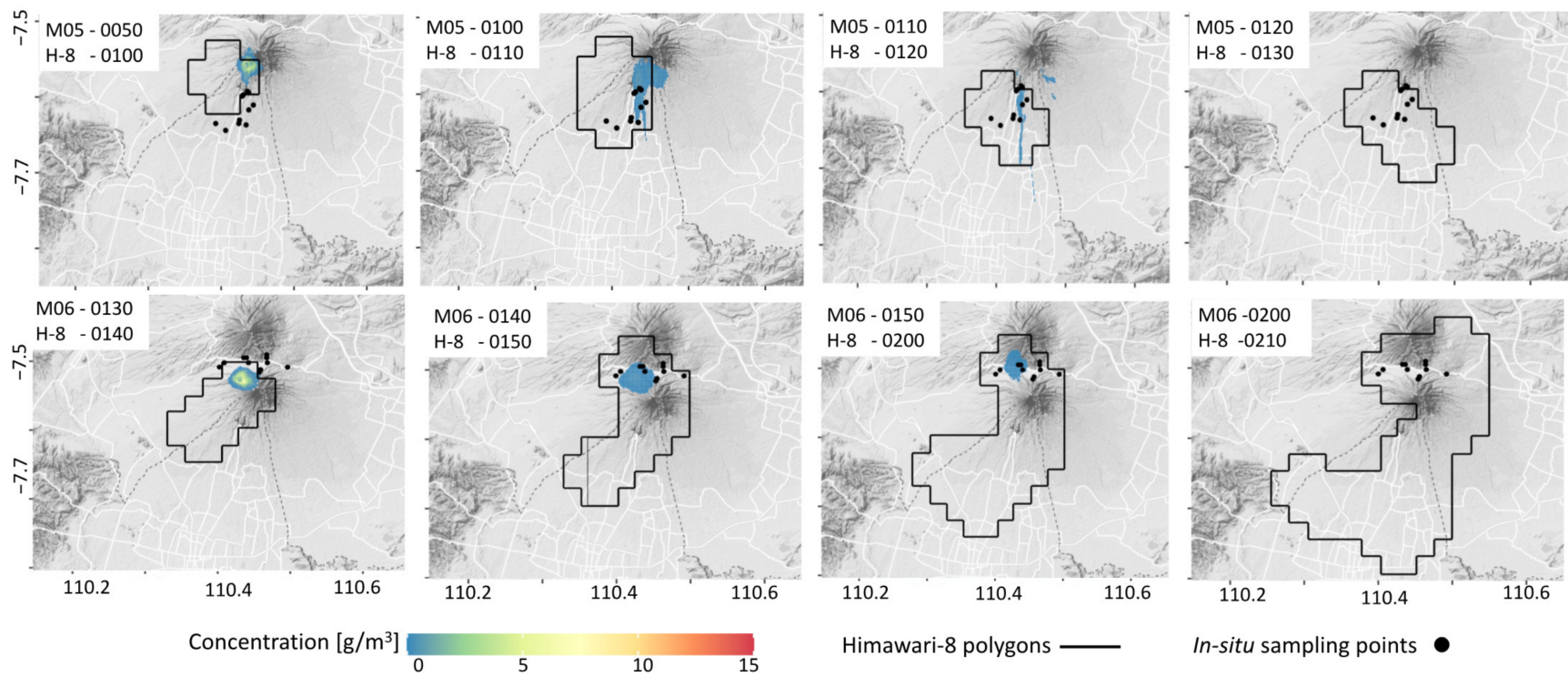

Figure 10. Mean ensemble of tephra concentration and area of detected tephra cloud by Himawari-8 (given by black polygons). The study cases and time stamps are indicated in the top left corner. The detected area of Himawari- 8 's tephra cloud was transformed into a polygon using cloud temperature $<285 \mathrm{~K}$. The ground-based data points are also presented in each map, given by black dots. In each image, the $x$ - and $y$-axis are longitude and latitude, respectively.

\section{Discussion}

\subsection{Tephra Detection}

Applying unwanted clutter cancellation is an important step in radar data processing. Here, we presented a simple procedure that could be easily included in the radar processing routine. In Table A3, an elevation angle $18^{\circ}$ had the highest probability of misclassification $(p=0.3)$, while other elevation angles performed relatively better $(p \leq 0.1)$. The misclassification can reduce the numbers of $Z_{H}$ s associated with tephra. As presented in Figure A1, a significant number of $Z_{H}$ pixels in the SW and NW sectors of M06 were removed at elevation angles of $15^{\circ}$ and $18^{\circ}$ after applying the NBC. Aggregating the $Z_{H}$ (max) from elevation angles of $13-21^{\circ}$ helped restore most of the data in the NW, but was still unable to reserve the echoes in the SE sector (Figure 2). This limitation is the consequence of a higher frequency of clutter in the SE sector. When the radar was pointing to the Merapi vent, the sidelobes were in contact with the hill side of Merapi (Turgo Hill, Figure $1 b$ ), producing unwanted radar noises in this sector.

Larger than $2 \mathrm{~mm}$ diameter particle $(\phi<-0.69)$ lasted only four minutes after the eruption in the atmosphere. This tephra regime was part of the eruptive mixture in the 
early development stages [41]. It should be noticed that larger and finer particles than the estimates may occur, unmonitored by the current method owing to the limitation of radar-retrieved GSD. The limitation is mainly related to radar specification (e.g., antenna gained, wavelength, radar sensitivity, and scanning speed). Larger tephra particles also fall faster, and such speed might be unmonitored by the 2 min temporal resolution of scanning radar. Moreover, some studies in tephra retrieval by the microphysical model of radar also found that intense tephra concentrations can be associated with greater amounts of finer and slower falling particles within a sampling volume $[9,19,20]$.

As noted earlier, we failed to extract radar estimates of GSD for M05 at two radar sampling points with available information of in situ data (P-01 and P-09, Figure 5). We could only extract the radar-retrieved GSD at some points near P-01. Notice that the in situ sampling points in Figure 5a were collected on surface level, while the radar-based model estimated the GSD at elevation angles of $13-21^{\circ}$ scans. Although this study assumed the observed radar parameters could represent the surface level, there was still uncertainty owing to atmospheric condition (i.e., wind profile) affecting the tephra distribution. Hence, some of radar images could not align well with the in situ data points [24]. While this study confirmed the incomparability between atmospheric and surface level data, we could use the grain size collected on ground data to constrain and compare the range of grain sizes inferred from radar. Point Q-01 and Q-09 are close and distal to the vent, respectively, and thus reflect the end members of the GSD for the whole sample region. However, based on the conclusion in [24], there was no significant difference between the sortation in both points, where they categorized the GSD to be moderately well sorted. The extracted radar-retrieved GSDs have limited distribution, where $\phi=0.85-1.25$. This limitation is related to the Rayleigh scattering theorem used in this study, which limits the $3.3 \mathrm{~cm}$ wavelength of radar to be associated with smaller than $\sim 2 \mathrm{~mm}$ mean particle diameter. Within the limited GSD range, our study could capture the spatial change in GSD, where the number of coarser particles decreases at a distant point from the radar. As presented on Figure 5e, Q-01 has a greater portion of coarse GSD than Q-09. Our estimates match the broadly predictable feature of GSD, which is a decrease in mean particle size with distance from the vent [42].

While the estimated GSD from the radar-retrieved model was slightly greater than the in situ data (for M06), the majority of radar-retrieved GSD fell within the range observed in [24] (Figure 3). More importantly, the radar-retrieved estimates of particle size also agreed with the conclusion of [24], that the tephra from M05 had a coarser grain size than M06 (Figure 5h,i). The difference between GSD for the two case study events can be attributed to the level of the eruption's explosivity and surface energy consumption. An eruption with lower explosion energy (M05) produced coarser grain pyroclastic deposits than the higher explosion energy (M06) [43,44]. However, it should be noted that the prediction of GSD from explosion energy is still an active area of research, and the variety of fragmentation processes and magma properties makes it difficult to construct a general relation between GSD and energy balance [44].

\subsection{Forecasting the Dispersal of Tephra}

Spatially, the mean EPS could track elevated tephra concentrations estimated by observed and valid $Z_{H}$. The initial conditions used have a significant role in the estimated tephra dispersal, where the longest and shortest time windows tend to have poorer predictive skills. The shortest time window (onset +4 ) members show the tendency of the tephra cloud to elongate in the $y$-direction (N-S), as it could not estimate the correct horizontal $u$-wind component (parallel to the $x$-axis: $\mathrm{E}-\mathrm{W}$ ), as presented in Figures A3 and A4. This signature is more visible in M05 than in M06, where the forecasted plume elongated in the NS direction (Figures 6 and 10). The plume expansion in the NS direction could also be attributed to the vertical growth or decaying rate, as it showed the change in altitude along with the range distance. As the radar is located in the SW sector, the altitude of the radar scan increases with radar's range in the $\mathrm{N}$ sector. The aggregated maximum $Z_{H}$ from 
different elevation angles $\left(13-21^{\circ}\right)$ may represent the actual growing or decaying rate at a different height. The ejected material with a higher concentration would have reached a higher altitude before expanding horizontally within a shorter period (onset +4 ). This result explained the more intense concentration estimates in the NW sector for both cases. Hence, the translation model might have calculated an increasing trend of $Z_{H}$ along the $y$-direction (NS), resulting in the NS elongated orientation of plume expansion. On the other hand, the most extended time window (onset +8 ) members showed an expansion of the plume to the $u$-wind component, indicating underestimation of the growth and decaying rate (Figures $\mathrm{A} 3$ and $\mathrm{A} 4$ ). At this time window, the identified plume had lost most of the intense $Z_{H}$ regime ( $>45 \mathrm{dBZ}$ ), causing an exaggeration of horizontal expansion.

Additionally, unlike precipitation, the advection vectors that determine the rotation and translation of tephra displacement were generated from fewer sample points, resulting in a higher error rate. Despite these limitations, this method has confirmed the timedependent plume evolution exhibited in short-lived Vulcanian eruptions [45]. We confirm a recommendation by a previous study [17] stating that, for EPS, the use of past data started too soon from the onset results in inferior predictive skill. However, it may also depend on the magnitude of eruption and the temporal scale of the instrument. As presented in this study, both cases are small-scale explosive events producing short-lived volcanic plumes. Generating the nowcasting using past data of the shortest (onset +4 ) and longest (onset +8 ) time window produces poorer results than using onset +6 as the initial condition. A longer time window, up to $6 \mathrm{~h}$ from the onset, was recommended in the satellite-based ensemble prediction of volcanic ash dispersal from the VEI-4 Kelud eruption [17]. This longer time window is not applicable for the short-lived plumes analysed by this study. For our study cases, onset +6 can probably better cover both the plume expansion (related to the energy release and ESP) and wind components (Figures 8, A3 and A4).

In the future, applying this method to larger magnitude eruptions will help answer the uncertainty of the optimum lead time applied to the nowcasting of the volcanic ash dispersal. A plume generated from a larger scale and more extended duration eruption event may last longer in the atmosphere and cover a broader area in the radar's azimuth display, enabling the addition of ensemble members for a more robust forecast. However, the forecast can be more challenging in the case of successive explosive pulses as they may not be suitable for a linear approach used in this study. Optimizing the nowcasting approach by the deep learning method has been considered effective in improving forecast quality. This method can solve non-linear precipitation phenomena, such as convective initiation [46].

The mean EPS can reduce the uncertainty of forecasted tephra track, spatially and temporally (Figures 6-9). Mean EPS took consideration from the mean values of ensemble members with $C_{a}>0.01 \mathrm{~g} / \mathrm{m}^{3}$. Hence, it removed the lowest probability forecasts, resulting in more reliable results that matched the estimated $C_{a}$ from radar observable. As EPS reduces the uncertainty of forecasts, it significantly improves prediction skills. In Figure 8, even though both CSI and POD show a typical behaviour of nowcasting, where it decreases following the time increase, the mean EPS maintained the prediction skill relatively better than ensemble members.

Estimating the growth and decaying rate for M06 is probably more challenging than M05, as given by CSI and POD scores. As the plume goes to the NW sector with a higher altitude, the maximum aggregate may contain higher $Z_{H}$ values (corresponding to higher $C_{a}$ ). Consequently, it produces more variability in the data distribution, which results in a higher error rate when estimating the $w$ parameter of some ensemble members. The poorest ensemble members forecast is given by combining all phenomena: parallel translation, rotation, and growth and decaying rate. The dispersion of the small size plume is mainly related to wind vectors and not by a mesoscale rotational motion, such as the case of a tropical cyclone. However, it should be noted that the higher predictability score given by $C S I$ and $P O D$ is based on large numbers of zero-valued pixels. The observed radar range was fixed at $30 \mathrm{~km}$ (Table 1) with a $150 \mathrm{~m}$ mesh resolution, resulting in significant 
$N_{\text {hit }}$ generated from pairs of zero-valued pixels but insignificant numbers of $N_{\text {false }}$ and $N_{\text {miss }}$ (Figure A5). Visual verification is crucial to conclude if each ensemble member can correctly imitate the tephra plume's movement and expansion.

Plume in M06 can maintain its circular shape that followed the radar-retrieved $C_{a}$, while plume in M05 has an elongated shape that does not match the radar-retrieved $C_{a}$. A different result is obtained when comparing the mean EPS with satellite data, where M05 is slightly better than M06. However, the scores are poorer than the comparison made with radar data. Poorer BS given by comparing radar nowcasting and satellite is reasonable owing to the different spatial patterns of the ash cloud seen by the two sensors because of the attenuation of different particle size sensitivity [31]. Himawari-8 infrared observation $\left(\lambda=10.4 \mu \mathrm{m}\right.$ for $\left.\mathrm{BTD}_{\mathrm{B} 13}\right)$ is more sensitive to capture finer particles than the $\mathrm{X}$-band radar observation $(\lambda=3.3 \mathrm{~cm})$. The difference is more noticeable for M06, as the undetected tephra plume of Himawari- 8 by the EPS model occurred in the $S$ sector, which has the lowest elevation scanned by radar. M05 has coarse GSD and distributes in the lower elevation within the radar's scanning range. The radar can observe the displacement in M05, enabling it to be modelled by nowcasting. Conversely, M06 has finer GSD and greater magnitude than M05. This may imply that the ejecta of M06 has greater exit velocity, which potentially helps raise the tephra mass to a higher altitude than M05, exceeding the radar's observable elevation angles. At higher altitudes, stronger wind shear can benefit the dispersal of the finer GSD of M06 in the S sector, as seen in Himawari-8 images. This regime of particles may also belong to the very-fine far travelling airborne ash mass, which can only be captured by satellites [46].

The detected tephra observed by radar are coarser than the satellite-based model [47], hence it is more likely to fall nearby the volcano because of its higher settling rate. This conclusion is supported by the spatial distribution of mean EPS that matches the distribution of tephra on the ground [24]. The detected plume by Himawari-8, on the other hand, had a much wider distribution within an area that did not belong to the in situ sampling area, especially for M06 (Figure 10). Hence, this study reveals the benefit of the X-band radar for a local early warning system in tephra hazard management, which is essential for the nearby population.

Even though the cloud temperature of Himawari-8 and estimated radar tephra concentration is not equally comparable owing to the difference in resolution, sensor's wavelength, and observed parameter, we assume that data from both instruments are complementary. Comparing data from both instruments helps differentiate tephra regimes that will fall earlier (ground-based radar) and parts of the finer ash regimes within a plume that may be transported at a higher altitude and potentially cause disruption to aviation (satellite). Moreover, the estimated tephra concentration from the radar is essential information for the characteristic of the plume in the lower altitude, which cannot be retrieved from the satellite data [17]. It also demonstrates the limitation of radar in observing the very fine airborne ash regime, which is captured by satellite.

\section{Conclusions}

This study has demonstrated the potency of an X-MP radar to detect and forecast tephra plume in Merapi. We estimated tephra concentration and GSD using solely groundbased radar data. We retrieved both tephra properties from two cases of explosive eruption: M05 and M06, based on radar's $Z_{H}$. Only valid $Z_{H}$ was used in the model as unwanted clutters and sidelobes contamination were automatically cancelled by the Bayesian approach. Using the microphysical model of radar, we found that higher than $7.5 \mathrm{~g} / \mathrm{m}^{3}$ tephra concentration lasted only 4 min after the onset. M05 has a coarser GSD than M06, which agrees with the in situ data. Applying the radar nowcasting in the manner of EPS reduced the uncertainty of forecasted tephra dispersal. However, the forecasts rely on radar observation with limited wavelength sensitivity and scanning range. Hence, it cannot forecast the very-fine ash regime transported to the higher than radar's elevation angles observation. Despite this limitation, the spatial distribution of the forecasted plume 
matches the distribution of tephra on the surface level, enforcing its potency in the early warning system for local people living nearby Merapi.

While more work is needed to apply the remote sensing approach of tephra plume tracking using ground-based weather radar, this study has presented the potential use of a weather radar to forecast the dispersal of tephra. A crucial problem is an uncertainty in estimating the growth and decaying rate. Capturing the dynamic of the tephra plume is challenging. Different eruptive cases may require more ensemble members than the one we presented here, or even different approaches, such as the deep learning method for a more robust forecast.

In order to overcome the limitation of observing only part of the volcanic plume with ground-based weather radar, future work should be more focused on integrating the radar and satellite data through data assimilation. Such a study will solve the classical problem of not detecting fine ash by radar observation while simultaneously improving the efficiency of the volcanic plume estimation by satellite data. This multisensory approach can reduce the complexity of tephra plume dispersion modelling and improve the reliability of its real-time forecasting using remote sensing techniques.

Supplementary Materials: Tephra radar-retrieved algorithms and its 2D visualization are coded in RStudio scripts and published on GitHub (https:/ / github.com/irasyarif1906/TephraRadar.git (accessed on 22 November 2021)).

Author Contributions: Conceptualization, M.S., R.I.H., S.F.J. and B.T.; methodology, M.S. and R.I.H.; software, M.S. and R.I.H.; validation, M.S., R.I.H. and Q.Y.; formal analysis, M.S.; investigation, M.S.; resources, M.S., S.F.J. and B.T.; data curation, N.A., D.L. and H.G.M.; writing-original draft preparation, M.S.; writing—review and editing, M.S., S.F.J., B.T., Q.Y., R.I.H. and A.B.A.; visualization, M.S.; supervision, S.F.J; project administration, N.A.; funding acquisition, S.F.J. and M.S. All authors have read and agreed to the published version of the manuscript.

Funding: This research was supported by the Earth Observatory of Singapore via its funding from the National Research Foundation Singapore and the Singapore Ministry of Education under the Research Centres of Excellence initiative. This work comprises EOS contribution number 420.

Institutional Review Board Statement: Not applicable.

Informed Consent Statement: Not applicable.

Data Availability Statement: Radar data used in this study and tephra tracking module (radar nowcasting) are available upon request.

Acknowledgments: We thank The Japan Science and Technology Agency for facilitating the installation of X-MP radar through Grant-in-Aid for Science and Technology Research Partnership for Sustainable Development Program (SATREPS). We are indebted to CVGHM and laboratory of Hydraulic, Department of Civil Engineering and Environment, Gadjah Mada University, which have supported us with the raw data of the X-MP radar. Himawari-8 gridded data are distributed by the P-Tree of the Japan Aerospace Exploration Agency (JAXA) Earth Observation Research Centre (EORC) and JMA. Finally, the authors wish to thank two anonymous reviewers for their valuable feedback to improve the manuscript.

Conflicts of Interest: The authors declare no conflict of interest.

\section{Appendix A. Naïve Bayesian Classifier}

A general expression of the Bayes classifier is given in Equation (A1). The classification is performed by applying the Bayes rule to calculate the probability of class $\mathrm{c}$, given a particular set of input measurements, and the prediction is

$$
p\left(c_{\alpha} \mid x_{1}, \ldots, x_{\beta}\right)=\frac{p\left(x_{1}, \ldots, x_{\beta} \mid c_{\alpha}\right) p\left(c_{\alpha}\right)}{p\left(x_{1}, \ldots, x_{\beta}\right)}
$$

In Equation (A1), $p\left(c_{\alpha} \mid x_{1}, \ldots, x_{\beta}\right)$ is the joint probability model, which can be simplified by assuming that all the input measurements are conditionally independent given the 
class label $c$. Subscript $\beta$ denotes number of parameters, which are 5 and 1 for clutter and tephra class classification, respectively. $p\left(c_{\alpha}\right)$ is the probability of the class label and subscript $\alpha$ has three and six classes for clutter cancelation and tephra detection, respectively.

Five input measurements for clutter classification are presented in Table A1. They are $Z_{H}$ and its standard deviation $\sigma\left(Z_{H}\right)$, altitude $\mathrm{z}, \rho_{H V}$, and frequency clutter map Pc. Pc was calculated by analysing a sufficient number of scans during a clear sunny day, which in this study was 210 sets of data for every nine elevation angles. These data were obtained from 1 July 2018 (07:00-12:00 UTC) to 31 May 2018 (22:00-24:00 UTC). Every pixel in each scan had a probability of occurrence of being clutter in the range of $0-1$. For instance, if a particular pixel was detected as an echo in clear conditions without prior information of rainfall or eruptive events 100 times out of 200, then the pixel has a $P c=0.5$. $P c$ was calculated in a similar way for every elevation angle.

Table A1. Input measurements of clutter classification.

\begin{tabular}{ccc}
\hline$Z_{H}$ & $\sigma\left(\boldsymbol{Z}_{\boldsymbol{H}}\right)$ & $z$ \\
\hline$\rho_{H V}$ & $P_{c}$ & \\
\hline
\end{tabular}

Training and test data for clutter classification were taken randomly from radar scanning data on 26-30 January 2018. Here, we assumed valid rainfall echo is similar to tephra. Figure A1 presents an example of the clutter cancellation results for elevation angles $15^{\circ}$ and $18^{\circ}$.

The tephra classification relied on a single input measurement of $Z_{H}$. The classification of tephra used six sets of synthetic data to train and test the Bayesian classifier. The synthetic data were generated using Gaussian distribution and the statistical parametrization is presented in Table A2. Two of the parameters were considered in generating the synthetic data: particle size and concentration. The synthetic data were generated with the assumption that the standard deviation was proportional to $20 \%$ and $50 \%$ from the mean values of particle diameter and concentration, respectively. Table contingency errors for clutter and tephra classification are given in Tables A3 and A4, respectively. The total probability along a column is always equal to one, whereas the input classes are listed in the columns.

Table A2. Statistical properties of synthetic tephra (modified from [9]).

\begin{tabular}{|c|c|c|c|c|c|}
\hline \multirow{3}{*}{\multicolumn{2}{|c|}{$\begin{array}{c}\text { Concentration } \\
\left(\mathrm{g} / \mathrm{m}^{3}\right)\end{array}$}} & \multicolumn{4}{|c|}{ Diameter of Particle Classes (mm) } \\
\hline & & \multicolumn{2}{|c|}{ Fine Class (F) } & \multicolumn{2}{|c|}{ Coarse Class (C) } \\
\hline & & Mean & Range & Mean & Range \\
\hline \multirow{2}{*}{ Light (L) } & Mean & \multirow{2}{*}{\multicolumn{2}{|c|}{$\begin{array}{c}0.10 \\
0.01-0.50\end{array}$}} & \multirow{2}{*}{\multicolumn{2}{|c|}{$\begin{array}{c}0.10 \\
0.01-0.50\end{array}$}} \\
\hline & Range & & & & \\
\hline \multirow{2}{*}{ Moderate (M) } & Mean & \multirow{2}{*}{\multicolumn{2}{|c|}{$\begin{array}{c}1.00 \\
0.50-2.00\end{array}$}} & \multirow{2}{*}{\multicolumn{2}{|c|}{$\begin{array}{c}1.00 \\
0.50-2.00\end{array}$}} \\
\hline & Range & & & & \\
\hline \multirow{2}{*}{ Intense (I) } & Mean & \multirow{2}{*}{\multicolumn{2}{|c|}{$\begin{array}{c}5.00 \\
2.00-10.00\end{array}$}} & \multirow{2}{*}{\multicolumn{2}{|c|}{$\begin{array}{c}5.00 \\
2.00-10.00\end{array}$}} \\
\hline & Range & & & & \\
\hline
\end{tabular}


Table A3. Contingency table of clutter classification by NBC.

\begin{tabular}{|c|c|c|c|c|}
\hline \multicolumn{2}{|c|}{ Class } & \multirow{2}{*}{$\begin{array}{c}\text { Clutter } \\
0.90\end{array}$} & \multirow{2}{*}{$\begin{array}{c}\text { Non-Clutter } \\
0.06\end{array}$} & \multirow{2}{*}{$\begin{array}{c}\text { Invalid } \\
0.00\end{array}$} \\
\hline & Clutter & & & \\
\hline Elevation angle $3^{\circ}$ & Non-Clutter & 0.10 & 0.94 & 0.00 \\
\hline & Invalid & 0.00 & 0.00 & 1.00 \\
\hline \multirow{3}{*}{ Elevation angle $5^{\circ}$} & Clutter & 0.96 & 0.04 & 0.00 \\
\hline & Non-Clutter & 0.04 & 0.96 & 0.00 \\
\hline & Invalid & 0.00 & 0.00 & 1.00 \\
\hline \multirow{3}{*}{ Elevation angle $7^{\circ}$} & Clutter & 0.98 & 0.04 & 0.00 \\
\hline & Non-Clutter & 0.02 & 0.96 & 0.00 \\
\hline & Invalid & 0.00 & 0.00 & 1.00 \\
\hline \multirow{3}{*}{ Elevation angle $9^{\circ}$} & Clutter & 0.98 & 0.03 & 0.00 \\
\hline & Non-Clutter & 0.02 & 0.97 & 0.00 \\
\hline & Invalid & 0.00 & 0.00 & 1.00 \\
\hline \multirow{3}{*}{ Elevation angle $11^{\circ}$} & Clutter & 0.99 & 0.03 & 0.00 \\
\hline & Non-Clutter & 0.01 & 0.97 & 0.00 \\
\hline & Invalid & 0.00 & 0.00 & 1.00 \\
\hline \multirow{3}{*}{ Elevation angle $13^{\circ}$} & Clutter & 1.00 & 0.03 & 0.00 \\
\hline & Non-Clutter & 0.00 & 0.97 & 0.00 \\
\hline & Invalid & 0.00 & 0.00 & 1.00 \\
\hline \multirow{3}{*}{ Elevation angle $15^{\circ}$} & Clutter & 0.95 & 0.02 & 0.00 \\
\hline & Non-Clutter & 0.05 & 0.98 & 0.00 \\
\hline & Invalid & 0.00 & 0.00 & 1.00 \\
\hline \multirow{3}{*}{ Elevation angle $18^{\circ}$} & Clutter & 0.99 & 0.30 & 0.00 \\
\hline & Non-Clutter & 0.01 & 0.70 & 0.00 \\
\hline & Invalid & 0.00 & 0.00 & 1.00 \\
\hline \multirow{3}{*}{ Elevation angle $21^{\circ}$} & Clutter & 1.00 & 0.10 & 0.00 \\
\hline & Non-Clutter & 0.00 & 0.90 & 0.00 \\
\hline & Invalid & 0.00 & 0.00 & 1.00 \\
\hline
\end{tabular}

Table A4. Contingency table of tephra classification by NBC.

\begin{tabular}{cccccccc}
\hline \multirow{2}{*}{ Class } & & \multicolumn{3}{c}{ F } & & & C \\
\cline { 3 - 7 } & & L & M & I & L & M & I \\
\hline \multirow{2}{*}{ F } & L & 0.94 & 0.19 & 0.04 & 0.02 & 0.00 & 0.00 \\
(Fine class) & M & 0.06 & 0.78 & 0.18 & 0.05 & 0.01 & 0.00 \\
& I & 0.00 & 0.04 & 0.76 & 0.14 & 0.02 & 0.01 \\
\hline C & L & 0.00 & 0.00 & 0.02 & 0.71 & 0.22 & 0.07 \\
(Coarse class) & M & 0.00 & 0.00 & 0.00 & 0.08 & 0.72 & 0.21 \\
& I & 0.00 & 0.00 & 0.00 & 0.00 & 0.04 & 0.72 \\
\hline
\end{tabular}



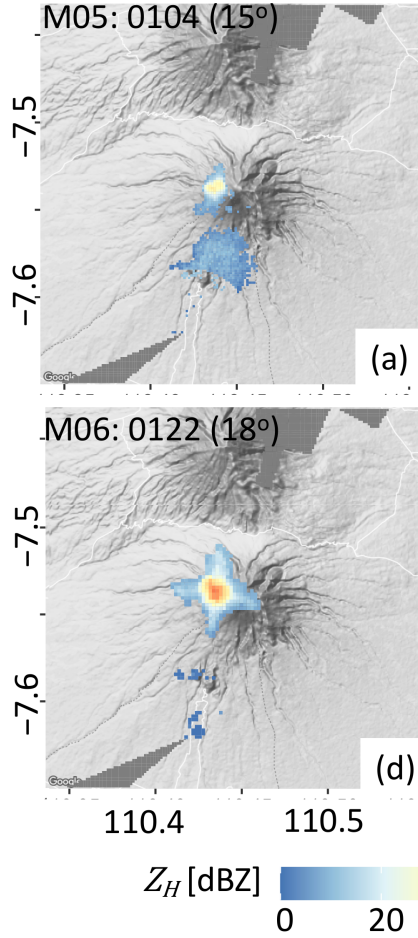

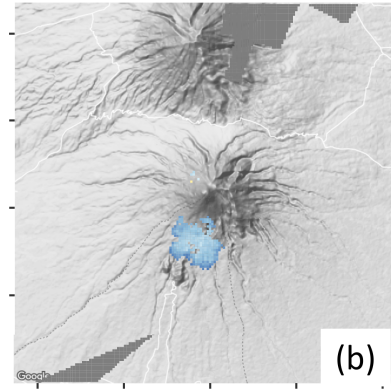

(b)
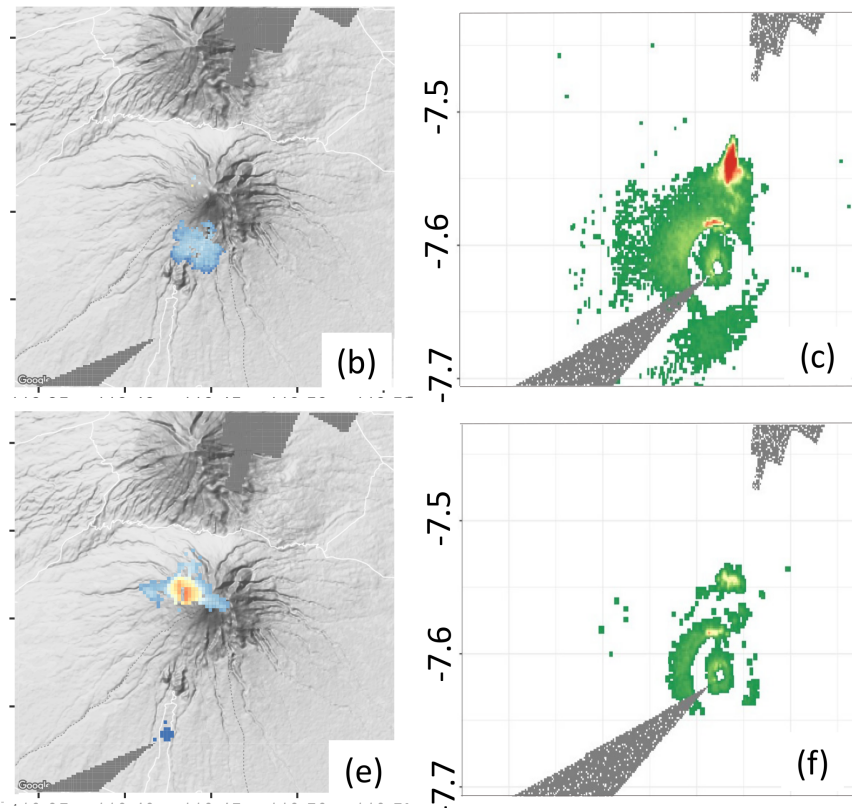

(e)

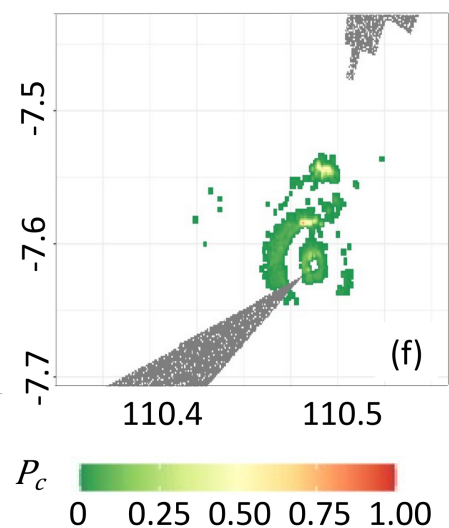

Figure A1. An example of the clutter cancellation results. Data are presented for elevation angles of 15 and $18^{\circ}$. The cases and time stamps are given in the top left corner. $(\mathbf{a}, \mathbf{d})$ The observed radar reflectivity intensity factor $Z_{H H},(\mathbf{b}, \mathbf{e})$ the filtered $Z_{H}$ after applying the clutter cancellation procedure, and $(\mathbf{c}, \mathbf{f})$ the frequency clutter map $P c$ for the given elevation angles. In each image, the $x$-axis is longitude and $y$-axis is latitude.

\section{Appendix B. Microphysical Radar Model of Tephra Retrieval}

The GSD of tephra is indicated by $N_{a}(D)$, where $D[\mathrm{~mm}]$ is the particle diameter. The gamma GSD as a general scaled form of $\left.N_{a}(D)\right)\left[\mathrm{m}^{-3} / \mathrm{mm}\right]$ is formally expressed as

$$
N_{a}(D)=N_{n}\left(\frac{D}{D_{n}}\right)^{\mu} e^{-\Lambda_{n}\left(\frac{D}{D_{n}}\right)^{v}}
$$

where $D_{n}[\mathrm{~mm}]$ is the number-weighted mean diameter; $N_{n}\left[\mathrm{~m}^{-3} / \mathrm{mm}\right]$ is the intercept; $\Lambda_{n}$ is the slope; $\mu$ is the shape factor; and $v$ is the slope factor. The normalization is such that $N_{n}$ and $\Lambda_{n}$ are related to the mean diameter $D_{n}$ and tephra concentration $C_{a}$, and have physical dimensions independent of $\mu$ and $v$. The GSD form follows the scaled gamma distribution, which is derived from the analogue form established for raindrops. The scaled gamma GSD $N_{S G}$ assumes that $v=1$, and follows an equation similar to Equation (A2):

$$
N_{S G}\left(D ; \mu, D_{n}, C_{a}\right)=N_{n G}\left(\frac{D}{D_{n}}\right)^{\mu} e^{-\Lambda_{n G}\left(\frac{D}{D_{n}}\right)}
$$

where the intercept parameter $N_{n G}$ and the slope parameter $\Lambda_{n G}$ were scaled using Equation (A4) and the tephra mass concentration was expressed in Equation (A5)

$$
\left\{\begin{array}{c}
N_{n G}=C_{a} \frac{6 D_{n}{ }^{\mu}}{\pi \rho_{a}(3+\mu) !}\left[\frac{(\mu+1) !}{D_{n}(\mu !)}\right]^{3+\mu+1} \\
\Lambda_{n G}=\mu+1 \\
C_{a}=\frac{\pi}{6} \rho_{a} m_{3}
\end{array}\right.
$$


The $n$-th moment of gamma distribution is given by

$$
m_{n}=\int_{D_{1}}^{D_{2}} D^{n} N_{a}(D) d D
$$

Assuming $\mu=1$, an explicit expression of the complete moment of gamma distribution (i.e., when $D_{1}=0$ and $D_{2}=\infty$ ) can be written as follows:

$$
m_{n G}=\frac{N_{n G}}{\left(\Lambda_{n G}\right)^{n+2}} D_{n}^{n+2-\mu} \Gamma(n+2)
$$

Here, $\Gamma$ is the gamma function. $N_{n G}$ and $\Lambda_{n G}$ are derived from Equation (A4). In the Rayleigh scattering assumption, $Z_{H}$ is given by the sixth moment of gamma distribution in Equation (A8). $Z_{H}$ can be expressed in $\mathrm{mm} / \mathrm{m}^{6}$ or $\mathrm{dBZ}$, which is $10 \log _{10}\left(Z_{H}\left[\mathrm{~mm} / \mathrm{m}^{6}\right]\right)$.

$$
Z_{H}=\int_{D_{\min }}^{D_{\max }} D^{6} N_{a}(D) d D=m_{6}
$$

The generated synthetic $Z_{H}$ was fitted against synthetic $C_{a}$ to formulate a statistical parametric model of $C_{a}-Z_{H}$ as follow:

$$
\hat{C}_{a}^{(c)}=\gamma\left[Z_{H}\right]^{\delta}
$$

where $\gamma$ and $\delta$ are the constants and the law-exponents. The apex $\left(^{\wedge}\right)$ indicates estimated quantity, and superscript $(c)$ indicates six classes of tephra (Table A2).

Appendix C. Spatiotemporal Forecasting of Tephra Evolution and Cross Validation
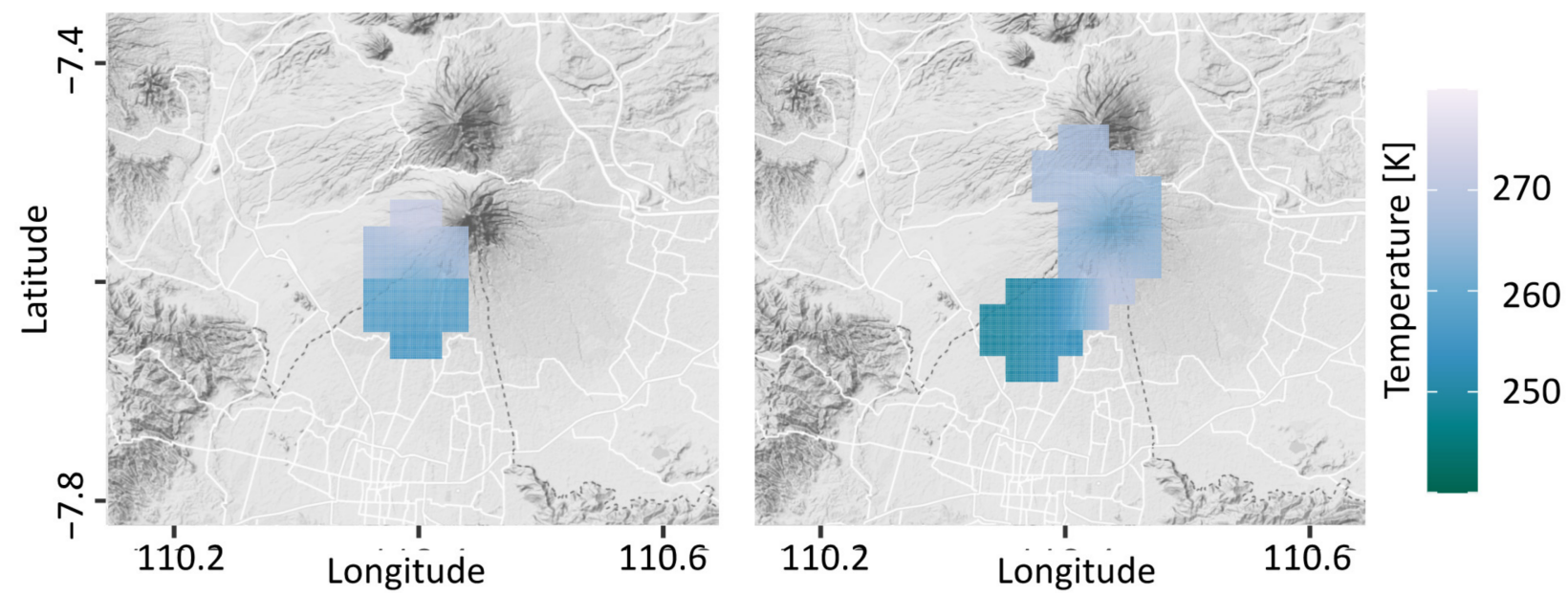

Figure A2. The bright temperature difference of band-13 (BTD $\left.{ }_{13}\right)$ of Himawari-8. Data are presented here for M05 (left) and M06 (right), $30 \mathrm{~min}$ after reported eruption onset, as indicated in the top left corner. 


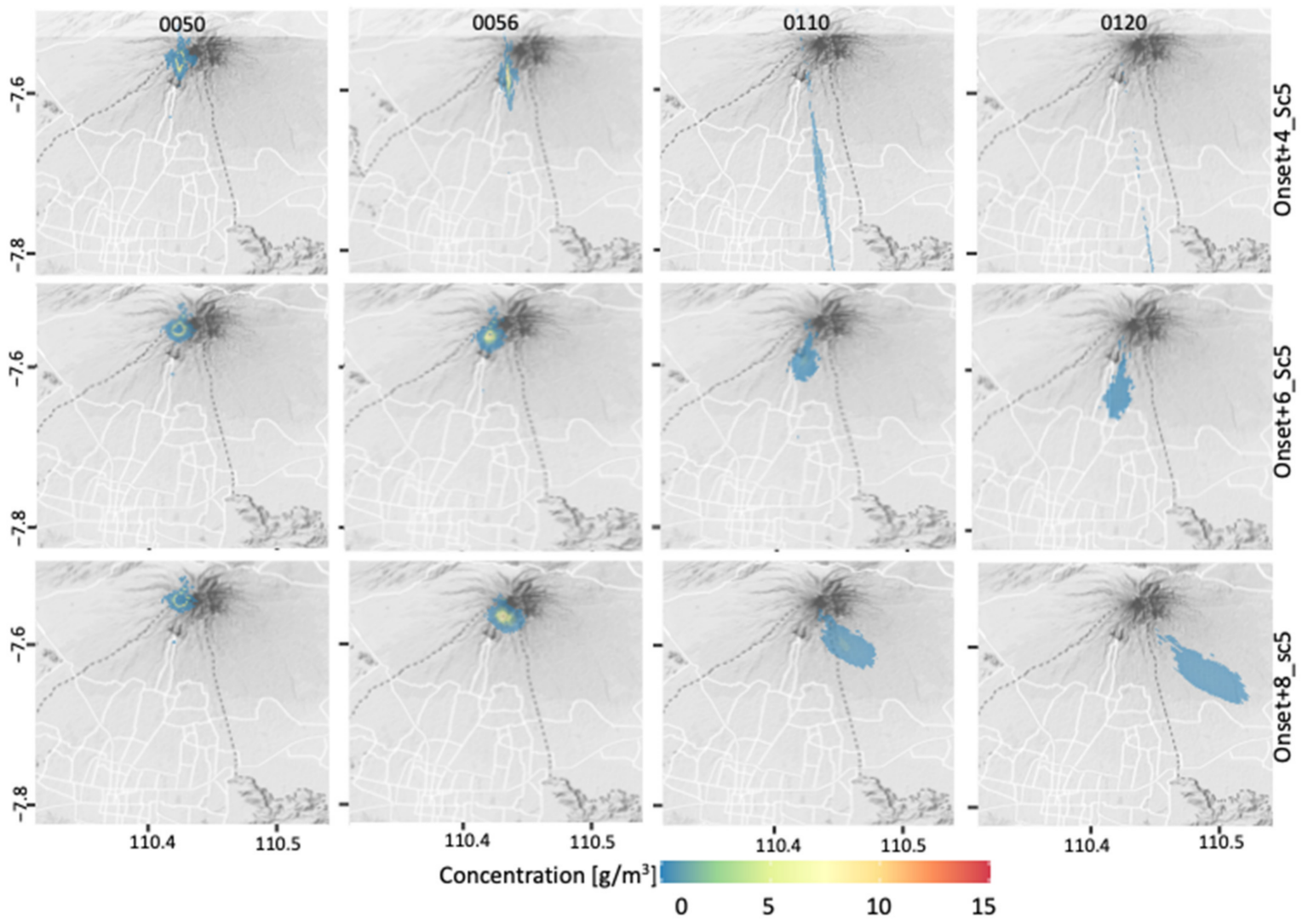

Figure A3. Some examples of the ensemble members (row) at different time step output (column). Presented is the nowcasting of M05. Each ensemble member was named based on the initial condition: onset $+i$ Sc $j$, where $i$ and $j$ represent the time in minutes and advection scenario (Table 3), respectively. In each image, the $x$-axis is longitude and $y$-axis is latitude.
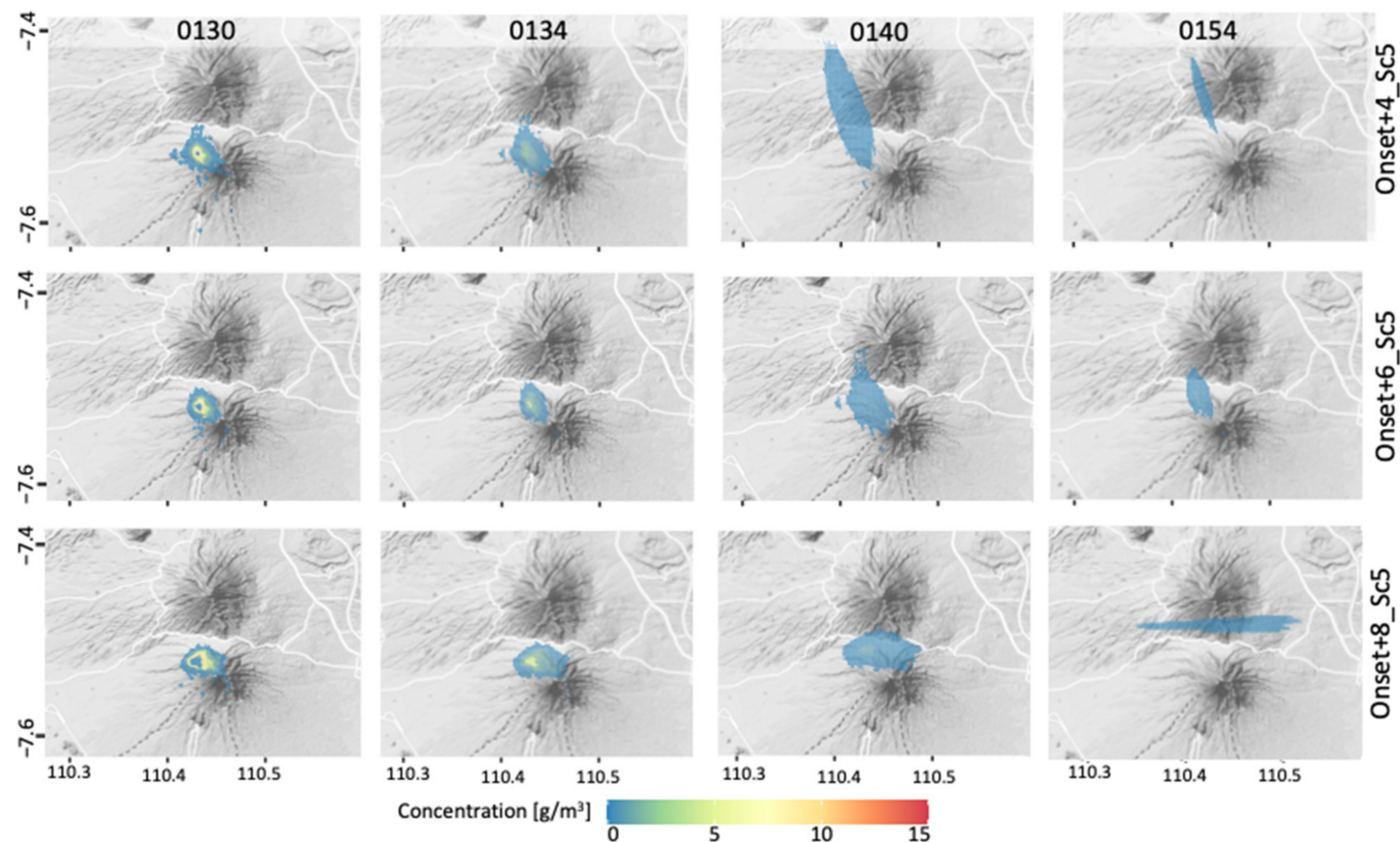

Figure A4. Some examples of the ensemble members (row) at different time step output (column). Presented is the nowcasting of M06. Each ensemble member was named based on the initial condition: onset $+i$ Sc $j$, where $i$ and $j$ represent the time in minutes and advection scenario (Table 3), respectively. In each image, the $x$-axis is longitude and $y$-axis is latitude. 

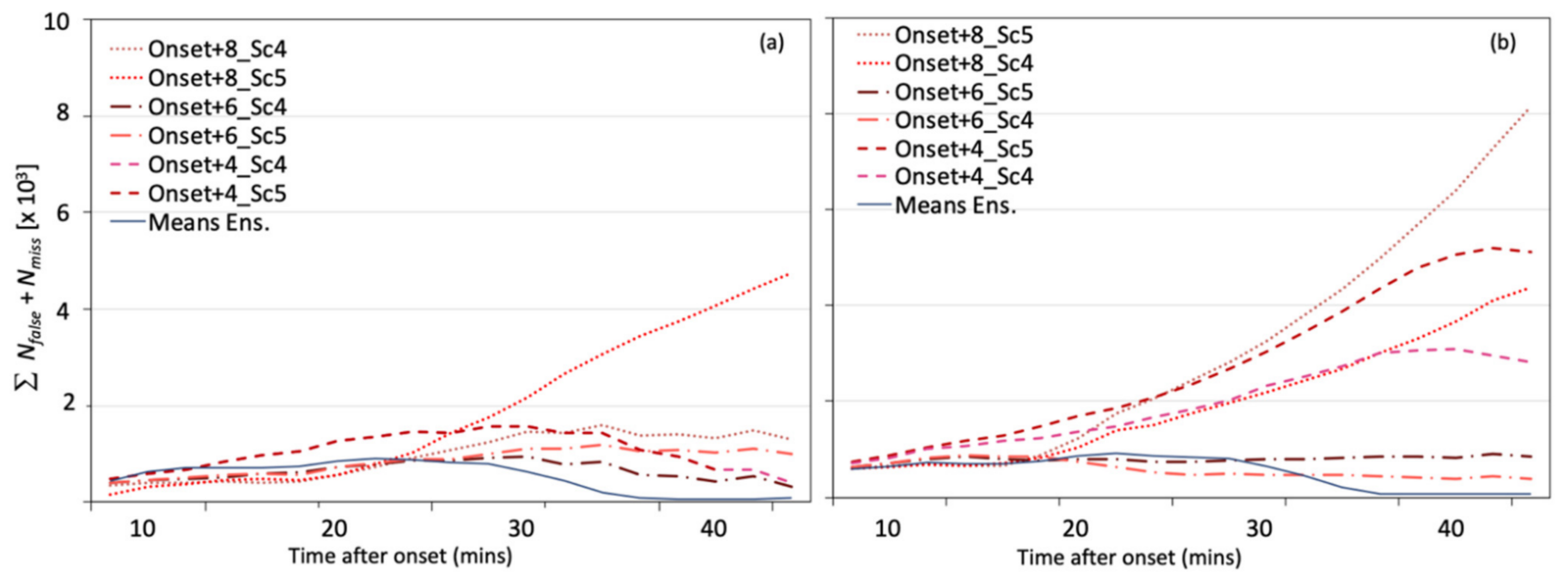

Figure A5. Number of missed and false events of ensemble members and the mean ensemble for M05 (a) and M06 (b).

\section{References}

1. Williams, G.T.; Jenkins, S.F.; Biass, S.; Wibowo, H.E.; Harijoko, A. Remotely assessing tephra fall building damage and vulnerability: Kelud Volcano, Indonesia. J Appl. Volcanol. 2020, 9, 10. [CrossRef]

2. Jenkins, S.F.; Wilson, T.M.; Magill, C.; Miller, V.; Stewart, C.; Blong, R.; Marzocchi, W.; Boulton, M.; Bonadonna, C.; Costa, A. Volcanic ash fall hazard and risk. In Global Volcanic Hazards and Risk; Loughlin, S., Sparks, S., Brown, S., Jenkins, S., Vye-Brown, C., Eds.; Cambridge University Press: Cambridge, UK, 2015; pp. 359-370. [CrossRef]

3. Jenkins, S.F.; Spence, R.J.S.; Fonesca, J.F.B.D.; Solidum, R.U.; Wilson, T.M. Volcanic risk assessment: Quantifying physical vulnerability in the built environment. J Volcanol. Geotherm. Res. 2014, 276, 105-120. [CrossRef]

4. Donnadieu, F.; Freville, P.; Hervier, C.; Coltelli, M.; Scollo, S.; Prestifilippo, M.; Valade, S.; Rivet, S.; Cacault, P. Near-source Doppler radar monitoring of tephra plumes at Etna. J. Volcanol. Geotherm. Res. 2016, 312, 26-39. [CrossRef]

5. Donnadieu, F. Volcanological Applications of Doppler Radars: A Review and Examples from a Transportable Pulse Radar in L-Band. In Doppler Radar Observations-Weather Radar, Wind Profiler, Ionospheric Radar, and Other Advanced Applications; Bech, J., Chau, J.L., Eds.; InTech: Urbino, Italy, 2012. [CrossRef]

6. Marzano, F.S.; Picciotti, E.; Di Fabio, S.; Montopoli, M.; Mereu, L.; Degruyter, W.; Bonadonna, C.; Ripepe, M. Near-Real-Time Detection of Tephra Eruption Onset and Mass Flow Rate Using Microwave Weather Radar and Infrasonic Arrays. IEEE Trans. Geosci. Remote Sen. 2016, 54, 6292-6306. [CrossRef]

7. Oishi, S.; Iida, M.; Muranishi, M.; Ogawa, M.; Hapsari, R.I.; Iguchi, M. Mechanism of volcanic tephra falling detected by X-band multi parameter radar. J. Disaster Res. 2016, 11, 43-45. [CrossRef]

8. Marzano, F.S.; Vulpiani, G.; Rose, W.I. Microphysical characterization of microwave radar reflectivity due to volcanic ash clouds. IEEE Trans. Geosci. Remote Sen. 2006, 44, 313-327. [CrossRef]

9. Marzano, F.S.; Vulpiani, G.; Barbieri, S.; Rose, W.I. Volcanic ash cloud retrieval by ground-based microwave weather radar. IEEE Trans. Geosci. Remote Sen. 2006, 44, 3235-3246. [CrossRef]

10. Montopoli, M.; Vulpiani, G.; Cimini, D.; Piccioti, E.; Marzano, F.S. Interpretation of observed microwave signatures from ground dual polarization radar and space multi-frequency radiometer for the 2011 Grímsvötn volcanic eruption. Atmos. Meas. Tech. 2014, 7, 537-552. [CrossRef]

11. Marzano, F.S.; Picciotti, E.; Montopolli, M.; Vulpiani, G. Inside volcanic clouds-Remote sensing of ash plumes using microwave weather radars. Bull. Am. Met. Soc. 2013, 94, 1567-1586. [CrossRef]

12. Shiiba, M.; Takasao, T.; Nakakita, E. Investigation of short-term rainfall prediction method by a translation model. Jpn. Conf. Hydraul. 1984, 28, 423-428.

13. Hapsari, R.I.; Oishi, S.; Sunada, K.; Sano, T. Improving flood simulation in urban river basin using X-band polarimetric radar and distributed hydrological model. Ann. J. Hydra. Eng. JSCE 2010, 54, 121-126.

14. Hapsari, R.I.; Oishi, S.; Sunada, K.; Nakakita, E.; Sano, T. Singular vector method on short-term rainfall prediction using radar for hydrologic ensemble prediction. Ann. J. Hydra. Eng. JSCE 2011,67, I_109-I_114. [CrossRef]

15. Hapsari, R.I. Development of Probabilistic Hydro-Meteorological Prediction for Urban Flood Disaster Prevention. Ph.D. Thesis, University of Yamanashi, Kofu, Japan, September 2011.

16. Hapsari, R.I.; Oishi, S.; Syarifuddin, M.; Asmara, R.A.; Legono, D. X-MP Radar for Developing a Lahar Rainfall Threshold for the Merapi Volcano Using a Bayesian Approach. J. Disaster Res. 2019, 14, 811-828. [CrossRef]

17. Zidikheri, M.J.; Lucas, C.; Potts, R.J. Quantitative verification and calibration of volcanic ash ensemble forecasts using satellite data. J. Geophys. Res.-Atmos. 2018, 123, 4135-4156. [CrossRef]

18. Corradini, S.; Merucci, L.; Folch, A. Volcanic ash cloud properties: Comparison between MODIS satellite retrievals and FALL3D transport model. IEEE Geosci. Remote Sens. 2011, 8, 248-252. [CrossRef] 
19. Syarifuddin, M.; Oishi, S.; Hapsari, R.I.; Shiokawa, J.; Mawandha, H.G.; Iguchi, M. Estimating the Volcanic Ash Fall Rate from the Mount Sinabung Eruption on February 19, 2018 Using Weather Radar. J. Disaster Res. 2019, 14, 135-150. [CrossRef]

20. Syarifuddin, M.; Oishi, S.; Nakamichi, H.; Maki, M.; Hapsari, R.I.; Mawandha, H.G.; Aisyah, N.; Basuki, A.; Loeqman, A.; Shimomura, M.; et al. A real-time tephra fallout rate model by a small-compact X-band multi-parameter radar. $J$ Volcanol. Geotherm. Res. 2020, 405, 107040. [CrossRef]

21. Syarifuddin, M.; Oishi, S.; Hapsari, R.I.; Legono, D.; Iguchi, M. Integrating X-MP Radar Data to Estimate Rainfall Induced Debris Flow in the Merapi Volcanic Area. Adv. Water Resour. 2017, 110, 249-262. [CrossRef]

22. Bringi, V.N.; Chandrasekar, V. Polarimetric Doppler Weather Radar: Principles and Applications; Cambridge University Press: Cambridge, UK, 2001.

23. Zrnic, D.; Melnikov, V. Ground Clutter Recognition Using Polarimetric Spectral Parameters. Preprints, 33rd Conf. on Radar Meteorology, Cairns, Australia. Amer. Meteor. Soc. p. P11B.13. Available online: https://ams.confex.com/ams/33Radar/ techprogram/paper_123205.htm (accessed on 20 November 2021).

24. Setijadji, L.D.; Jesslyn, J.; Situmorang, N.G.; Wiguna, A. 2018 Eruption of Merapi: The Interpretation of Eruption Type Based on Volcanic Material Study from Explosive Eruption on May 11 and June 1, 2018 (in Bahasa Indonesia). Proceeding Seminar Nasional Kebumian 11. Yogyakarta, Indonesia, 5-6 September; 2018, pp. 908-917. Available online: https://repository.ugm.ac.id/2749 20/1/OVK-3_ERUPSI\%20MERAPI\%202018\%20INTERPRETASI\%20JENIS\%20ERUPSI\%20BERDASARKAN\%20STUDI\%20 MATERIAL\%20VULKANIK\%20HASIL\%20ERUPSI\%20EKSPLOSIF\%2011\%20MEI\%20DAN\%201\%20JUNI\%20201.pdf (accessed on 15 August 2020).

25. Budi-Santoso, A.; Humaida, H.; Sulistiyani; Aisyah, N.; Putra, R. The 2018 phreatic eruption, an Indication of new magmatism episodes of Merapi. In Bahasa Indonesia: Letusan Freatik 2018 Indikasi Episode Baru Aktivitas Magmatis G. Merapi. Bul. Merapi Ed. Agustus 2018, 22, 12-38.

26. Centre for Volcanology and Geological Hazard Mitigation (CVGHM). Press release of Mt. Merapi on June 6, 2018, at 10:00 (in Bahasa Indonesia). 2018. Available online: http:/ / merapi.bgl.esdm.go.id/pub/page.php?idx=321 (accessed on 28 January 2019).

27. Furuno. Operator Manual: Compact X-Band Dual Polarimetric Weather Doppler Radar, Type WR-2100, Japan. 2014. Available online: https:/ / www.furuno.com/en/systems/meteorological-monitoring/WR2120 (accessed on 20 November 2021).

28. Rico-Ramirez, M.A.; Cluckie, I.D. Classification of ground clutter and anomalous propagation using dual-polarization weather radar. IEEE Trans. Geosci. Remote Sens. 2008, 46, 1892-1904. [CrossRef]

29. Lacasse, C.; Karlsdóttir, S.; Larsen, G.; Soosalu, H.; Rose, W.I.; Ernst, G.G.J. Weather radar observations of the Hekla 2000 eruption cloud, Iceland. Bull. Volcanol. 2004, 66, 457-473. [CrossRef]

30. Maki, M.; Iguchi, M.; Maesaka, T.; Miwa, T.; Tanaka, T.; Kozono, T.; Momotani, T.; Yamaji, A.; Kakimoto, I. Preliminary Results of Weather Radar Observations of Sakurajima Volcanic Smoke. J. Disaster Res. 2016, 11, 15-30. [CrossRef]

31. Maki, M.; Kim, Y.; Kobori, T.; Hirano, K.; Lee, D.-I.; Iguchi, M. Analyses of three-dimensional weather radar data from volcanic eruption clouds. J. Volcanol. Geotherm. Res. 2021, 412, 107178. [CrossRef]

32. Marzano, F.S.; Barbieri, S.; Piccioti, E.; Karlsdottir, S. Monitoring sub-glacial volcanic eruptions using C-band radar imagery. IEEE Trans. Geosci. Remote Sens. 2009, 48, 403-414. [CrossRef]

33. Corradini, S.; Montopoli, M.; Guerrieri, L.; Ricci, M.; Scollo, S.; Merucci, L.; Marzano, F.S.; Pugnaghi, S.; Prestifilippo, M.; Ventress, L.J.; et al. A Multi-Sensor Approach for Volcanic Ash Cloud Retrieval and Eruption Characterization: The 23 November 2013 Etna Lava Fountain. Remote Sens. 2016, 8, 58. [CrossRef]

34. Vinodkumar, K.; Chandrasekar, A. Ensemble Lagged Forecasts of a Monsoon Depression over India Using a Mesoscale Model. Atmosfera 2007, 20, 25-44.

35. Bivand, R.; Keitt, T.; Rowlingson, B. Rgdal: Bindings for the "Geospatial” Data Abstraction Library, R-Package Version 1.5-18. 2020. Available online: https:/ /CRAN.R-project.org/package=rgdal (accessed on 20 November 2021).

36. Kahle, D.; Wickham, H. ggmap: Spatial visualization with ggplot2. R J. 2013, 1, 144-161. [CrossRef]

37. Bessho, K.; Date, K.; Hayashi, M.; Ikeda, A.; Imai, T.; Inoue, H.; Kumagai, Y.; Miyakawa, T.; Murata, H.; Ohno, T.; et al. An introduction to Himawari-8/9-Japan's new-generation geostationary meteorological satellites. J. Meteor. Soc. Jpn. 2016, 94, 151-183. [CrossRef]

38. Shimizu, A. Introduction to Himawari-8 RGB Composite Imagery. Meteorological Satellite Centre Technical Note. No.65. October 2020. Available online: https://www.data.jma.go.jp/mscweb/technotes/msctechrep65-1.pdf (accessed on 20 November 2021).

39. Roebber, P.J. Visualizing multiple measures of forecast quality. Weather. Forecast. 2009, 24, 601-608. [CrossRef]

40. Wilks, D.S. Statistical Methods in the Atmosphere; Academic Press: Cambridge, MA, USA, 2011.

41. Tournigand, P.-Y.; Taddeucci, J.; Gaudin, D.; Peña Fernández, J.J.; Del Bello, E.; Scarlato, P.; Kueppers, U.; Sesterhenn, J.; Yokoo, A. The initial development of transient volcanic plumes as a function of source conditions. J. Geophys. Res. 2019, 122, 9784-9803. [CrossRef]

42. Cutler, N.A.; Streeter, R.T.; Dugmore, A.J.; Sear, E.R. How do the grain size characteristics of a tephra deposit change over time? Bull Volcanol. 2012, 83, 45. [CrossRef]

43. Walker, G.P.L. Explosive Volcanic Eruptions-A New Classification Scheme. Geol. Rundsch. 1973, 62, 431-446. [CrossRef]

44. Gonnermann, H.M. Magma Fragmentation. Annu. Rev. Earth 2015, 43, 431-458. [CrossRef] 
45. Scase, M.; Caulfield, C.; Dalsiel, S.; Hunt., J. Time-dependent plumes and jets with decreasing source strengths. J. Fluid Mech. 2006, 563, 443-461. [CrossRef]

46. Ayzel, G.; Scheffer, T.; Heistermann, M. Rainnet v1.0: A convolutional neural network for radar-based precipitation nowcasting. Geosci. Mod. Dev. 2020, 13, 2631-2644. [CrossRef]

47. Poret, M.; Corradini, S.; Merucci, L.; Costa, A.; Andronico, D.; Montopoli, M.; Vulpiani, G.; Freret-Lorgeril, V. Reconstructing volcanic plume evolution integrating satellite and ground-based data: Application to the 23 Novemberr 2013 Etna Eruption. Atmos. Chem. Phys. 2018, 18, 4695-4714. [CrossRef] 